Five-year Survival Rate Of Bonded Dental Restorations In Frail Older Adults

by

Nicholas Tong

A THESIS SUBMITTED IN PARTIAL FULFILLMENT OF

THE REQUIREMENTS FOR THE DEGREE OF

MASTER OF SCIENCE

in

THE FACULTY OF GRADUATE AND POSTDOCTORAL STUDIES

(Craniofacial Science)

THE UNIVERSITY OF BRITISH COLUMBIA

(Vancouver)

June 2019

(C) Nicholas Tong, 2019 
The following individuals certify that they have read, and recommend to the Faculty of Graduate and Postdoctoral Studies for acceptance, a thesis/dissertation entitled:

\section{Five-Year Survival Rate Of Bonded Dental Restorations In Frail Older Adults}

$\begin{array}{ll}\text { submitted by } & \text { Nicholas Tong in partial fulfillment of the requirements for } \\ \text { the degree of } & \text { Master of Science } \\ \text { in } & \text { Craniofacial Science }\end{array}$

\section{Examining Committee:}

Dr. Christopher Wyatt

Supervisor

Dr. Adriana Manso

Supervisory Committee Member

Dr. Jolanta Aleksejuniene

Supervisory Committee Member

Additional Examiner

Additional Supervisory Committee Members:

Supervisory Committee Member

Supervisory Committee Member 


\section{Abstract}

Objectives: Frail older adults who reside in long-term care (LTC) facilities are among the most vulnerable to dental caries due to poor oral hygiene $(\mathrm{OH})$, medication-related salivary hypofunction, diets high in carbohydrates, and limited access to dental care. Providing dental restorations for LTC patients is challenging and there is a lack of studies investigating the longevity of dental restorations in this cohort. Over the years, multiple dental restorative materials have been used to restore tooth anatomy in an aesthetic manner as well as to address dental caries prevention using fluoride-based materials. This study examined the longevity of direct bonded dental restorations placed in LTC patients. Specifically, we aimed to determine if there is a difference in survival between resin composite (RC) and glass ionomer cement (GIC) direct restorations in frail older adults residing in LTC.

Methods: Tooth-coloured restorations placed in LTC patients between 2007-2012, within the University of British Columbia Geriatric Dentistry Program, were followed annually up to five years or until they incurred an event (i.e. re-restoration or tooth extraction), or the patient was lost to follow-up or deceased. Restoration status was documented within the Clinical Oral Disorder in Elders (CODE) Index annual oral health assessments. Mixed-effect logistic regression was calculated to determine hazard ratios, address within-patient correlation and measure the effect size of multiple covariates.

Results: A total of 3,201 dental restorations placed in 846 LTC patients were followed. This cohort of patients had a mean age of 86 years, high levels of oral disease, systemic disease and polypharmacy, and had on average 2.5 carious teeth at presentation. Over $50 \%$ of patients were wheelchair-bound and had compromised ability to perform $\mathrm{OH}$. The overall 5-year survival rate 
was $60.3 \%$ overall and there was no statistically significant difference in survival rates between $\mathrm{RC}$ and GIC restorations.

Conclusion: Tooth-coloured dental restorations had reasonable longevity in LTC patients and had comparable survival to restorations placed in functionally independent, community-dwelling geriatric populations. No difference between RC and GIC was found with regards to restoration longevity in this population. 


\section{Lay Summary}

Older adults living in long-term care (LTC) facilities are at high risk of oral disease due to multiple medical problems, poor oral hygiene, and numerous barriers to dental care. Dental decay is common amongst these patients and there is a substantial need for dental fillings to prevent tooth loss, minimize pain, maintain chewing function, and optimize quality of life. In this study, the longevity of two tooth-coloured filling materials in LTC patients over five years was investigated and found to be comparable to that in other community-dwelling older adult groups. From our results, we can conclude that $\sim 60 \%$ of these types of fillings, placed in LTC patients, will survive until the end of patients' life. 


\section{Preface}

The identification, design, and performance of this research project was conducted by Dr.

Nicholas Tong. Dr. Chris Wyatt aided with the overall design and methodology of the project, alongside committee members, Drs. Manso and Aleksejuniene.

Statistical analysis of research data was conducted by Eric Fu, Carolyn Taylor, and the ASDa group at the UBC Department of Statistics after consultation with Drs. Tong and Wyatt.

UBC Clinical Research Ethics Board (CREB): H18-02077

Data collection and analysis was performed by Dr. Nicholas Tong. A summer research assistant, Seyedeh Sara Hamidi, helped with collecting a portion of the data used for analysis. Writing of the thesis was performed solely by Dr. Nicholas Tong, with editing by Dr. Chris Wyatt.

Publications arising from work presented in the thesis: None at this time. 


\section{Table of Contents}

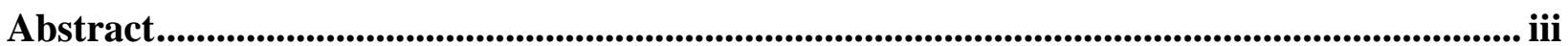

Lay Summary ...................................................................................................................................

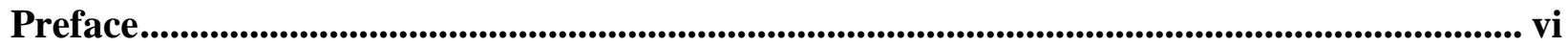

Table of Contents .............................................................................................................. vii

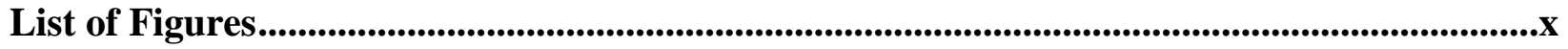

List of Abbreviations ................................................................................................................ xi

Acknowledgements ......................................................................................................................................... xii

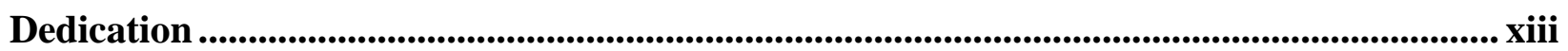

Chapter 1: Introduction ...........................................................................................................................................1

$1.1 \quad$ Geriatrics: Trends in General Health and Oral Health................................................ 1

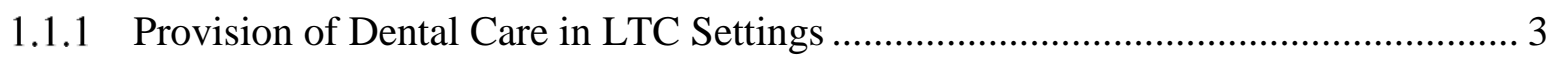

1.1 .2 CODE Index

1.1.3 Challenges in the Management of a Geriatric Dental Patient.................................. 10

1.1.3.1 Physical Frailty ................................................................................. 10

1.1.3.2 Cognitive Decline ……………................................................................ 11

1.1.3.3 Social Factors and Other Barriers to Dental Care............................................. 15

1.1.4 Rational Treatment Planning for the Geriatric Patient ........................................... 17

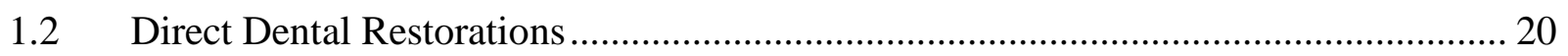

1.2.1 Selection of Direct Dental Restorative Materials ................................................... 20

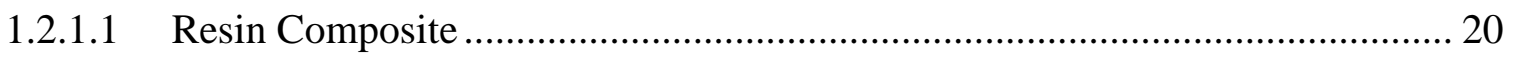

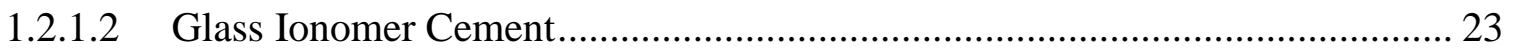


1.2.2 Clinical Assessment of Restorations in Dental Research ................................... 26

1.2.3 Conventional and Atraumatic Restorative Technique ......................................... 28

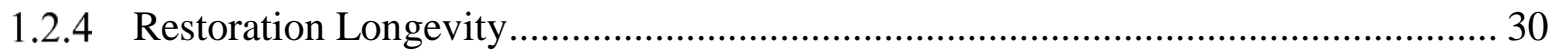

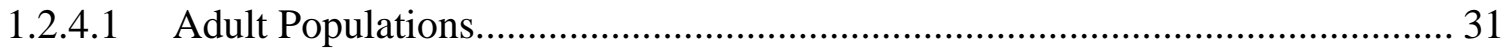

1.2.4.2 Pediatric Populations ............................................................................ 35

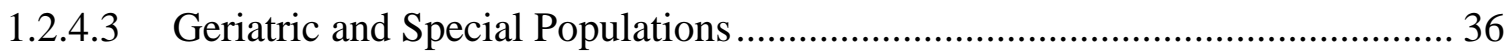

1.2.5 Factors Affecting Restoration Longevity...................................................... 38

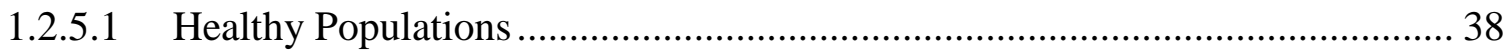

1.2.5.2 Geriatric and Special Patient Populations .................................................. 41

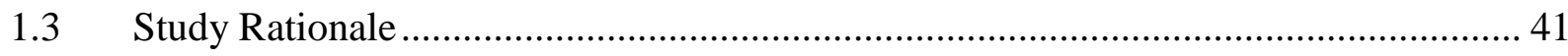

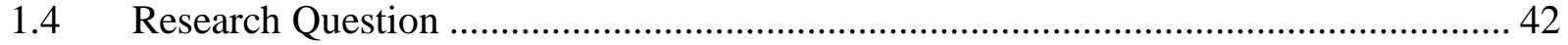

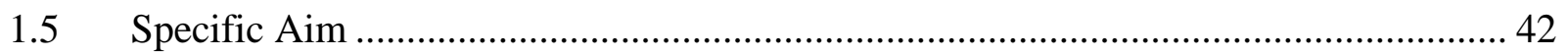

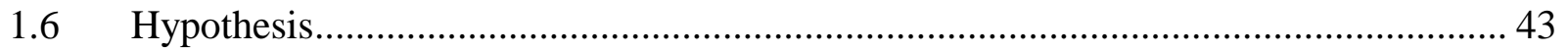

Chapter 2: Materials and Methods ..................................................................................................44

2.1 Materials and Methods................................................................................... 44

2.1.1 Statistical Analysis and Sample Size Calculation.............................................. 46

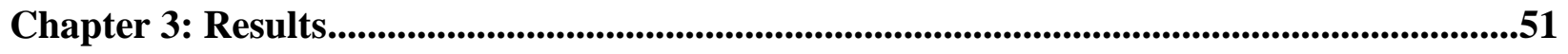

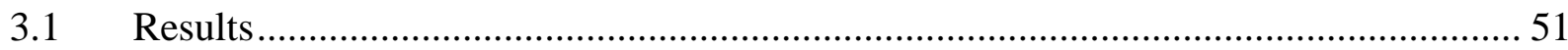

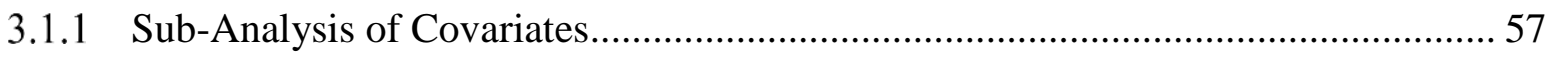

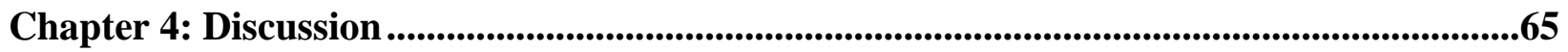

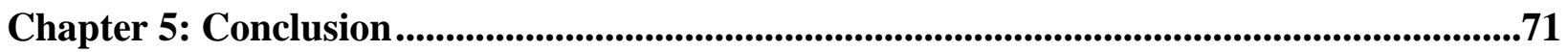

References.................................................................................................................................................................72 


\section{List of Tables}

Table 1-1 Components of CODE Index Relating to Jaw Function ${ }^{19}$....................................... 7

Table 1-2 Components of the CODE Index Relating to Maxillary/Mandibular Removable

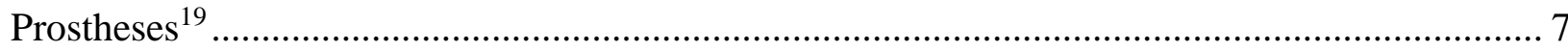

Table 1-3 Components of the CODE Index relating to Mucosal Disorders ${ }^{19}$........................... 8

Table 1-4 Components of the CODE Index relating to Tooth Structures ${ }^{19}$.............................. 9

Table 1-5 Components of the CODE Index relating to a Gingival Health and Periodontium ${ }^{19}$..... 9

Table 1-6 Activities of Daily Living and Instrumental Activities of Daily Living ${ }^{22}$................. 14

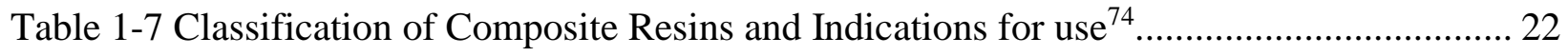

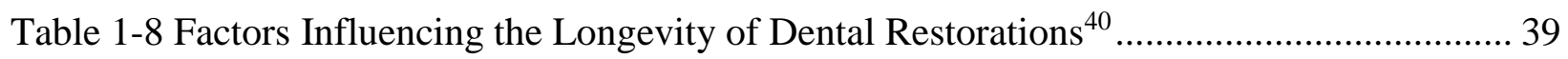

Table 2-1 Sample Size Projection based on Pilot Study Results .......................................... 47

Table 3-1 Crude Survival Probabilities for Tooth-Coloured Restorations ................................. 54

Table 3-2 Number of Restorations at risk, failed, and lost to follow-up .................................. 55

Table 3-3 Odds Ratio from Mixed Effect Logistic Regression (Unadjusted Analysis) .............. 56

Table 3-4 Baseline Characteristics of Study Sample ........................................................ 58

Table 3-5 Estimated Odds Ratios- Unadjusted model ................................................... 61

Table 3-6 Chi-squared tests for covariate effects (Type III Sum of Squares)- Unadjusted model62

Table 3-7 Estimated odds ratios for covariate-Adjusted Model ............................................ 63

Table 3-8 Chi-squared tests for treatment and covariate effects (Type III Sum of Squares) -

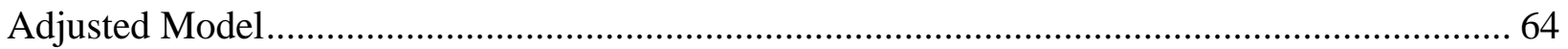




\section{List of Figures}

Figure 3-1 Total Number of Restorations per Patient, excluding Caries Control Restorations ... 52

Figure 3-2 5-Year Trend of Total Restorations Placed and Restoration Material Usage ............ 53

Figure 3-3 Crude Survival Probabilities for Tooth-Coloured Restorations............................... 54

Figure 3-4 Mixed Effect Logistic Regression Model for 5-year Survival of Tooth-Coloured

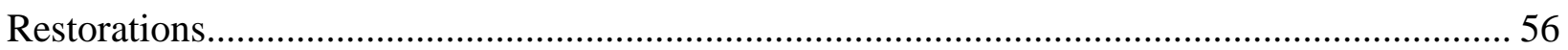




\section{List of Abbreviations}

\begin{tabular}{|c|c|}
\hline ADL & Activities of daily living \\
\hline AFR & Annual failure rate \\
\hline AM & Amalgam \\
\hline ASDa & Applied Statistics and Data Science \\
\hline BCDA & British Columbia Dental Association \\
\hline CODE & Clinical Index of Oral Disorder in Elders \\
\hline DO & Distal-occlusal \\
\hline GIC & Glass ionomer cement \\
\hline GDP & Geriatric dentistry program \\
\hline HR & Hazard ratio \\
\hline IADL & Instrumental activities of daily living \\
\hline LTC & Long-term care facility \\
\hline MCI & Mild cognitive impairment \\
\hline MO & Mesial-occlusal \\
\hline NCCL & Non-carious cervical lesions \\
\hline OA & Osteoarthritis \\
\hline OR & Odds ratio \\
\hline OHRQoL & Oral health-related quality of life \\
\hline $\mathrm{RC}$ & Resin composite \\
\hline $\mathrm{RCT}$ & Randomized Control Trials \\
\hline RR & Relative risk \\
\hline UBC & University of British Columbia \\
\hline
\end{tabular}




\section{Acknowledgements}

I offer my enduring gratitude to the faculty, staff and my fellow students at UBC, who have inspired me to continue my work in the field of geriatric dentistry. I owe particular thanks to Dr. Chris Wyatt, who has been a true mentor and friend to me throughout my undergraduate, dental, and post-graduate training.

Thank you to the staff at the UBC Geriatric Dentistry Program who have worked tirelessly for so many years to serve vulnerable patients living in long-term care and assisted living in BC. Specifically, special thanks to Shunhau To for her years of hard work and support for me during my education and early career.

Thank you to Dr. Bill Preshing, director of the GPR program at the University of Alberta Hospital, for inspiring me and a generation of dental residents to care for medically compromised patients. You served as a role model in dentistry and in life.

I would also like to thank Peter Hinz and Wei Zhang, who graciously aided me with record finding and data management in Axium. Thank you to Eric Fu, Carolyn Taylor, and the ASDa group at the UBC Department of Statistics for your thoughtful help with statistical analysis and advice for our project. Furthermore, Seyedeh Sara Hamidi, a UBC summer research assistant, also helped with data collection for this project. Thank you all so much for your help. 


\section{Dedication}

I dedicate this project to my wife, Dr. Alice Chen. Thank you for your love and endless support of me throughout the wonderful journey we have taken together.

Thank you to my parents, Janice Tong and Dr. Aloysius Tong, and my aunt, Dr. Christina Tong, for a lifetime of privilege and joy that you worked hard to give me and our family. 


\section{Chapter 1: Introduction}

\subsection{Geriatrics: Trends in General Health and Oral Health}

Canada's population is aging, with more than $25 \%$ of the total population expected to be over age 65 by $2035 .{ }^{1}$ As a group, Canadian older adults aged 85 years or older grew by nearly $20 \%$ from 2011 to 2016, which represents a growth rate four times that of the overall national average of $5 \% .{ }^{1}$ By 2031 , the baby boomer cohort, born between 1946-1965, will reach age 85 , which will be associated with a rapid increase in this cohort's proportion of Canada's total population. ${ }^{1}$ In Canada, it is expected that there will be approximately 2.7 million people aged 85 or older by 2051. ${ }^{1}$ In the US, the population of older adults is expected to increase by over $90 \%$ by $2050 .{ }^{2}$ As life expectancy increases, these changing demographics will have a significant impact on society and our health care system, as older adults have more chronic diseases. ${ }^{3,4}$ Chronic noncommunicable diseases are common amongst older adults, the most common ones being dementia, stroke, chronic obstructive pulmonary disease and vision impairment. ${ }^{3}$ These chronic diseases, which disproportionately affect older adults, are important to society as their burden arises more from disability than from mortality. ${ }^{3}$ The societal costs from these diseases are currently large and may become tremendous. ${ }^{3}$

Chronic disease and disability associated with ageing are linked to poor oral health. ${ }^{5}$ It has been suggested that poor oral health can be used to predict functional decline in the performance of activities of daily living (ADL) and instrumental activities of daily living (IADL). ${ }^{5}$ Past reports have also suggested that oral disorders affect quality of life and general health, and have emphasized the need to improve oral health for this segment of the population. ${ }^{6,7}$ Most older adults live in the community while approximately $5 \%$ of older adults in Canada currently reside 
in long-term care (LTC) facilities. ${ }^{8,9}$ Older adults in Canada are typically admitted to LTC due to complex multimorbidity, advanced cognitive decline, or both, or can no longer be safely cared for in their own homes or in assisted living residences. ${ }^{9}$ This is a vulnerable segment of the population with respect to oral health as this cohort has multiple barriers in accessing dental care. ${ }^{7}$ Apart from multiple medical co-morbidities and cognitive decline, other barriers to optimal oral health include poverty and LTC staff inadequately trained to provide appropriate daily oral hygiene $(\mathrm{OH})^{7}$

Dental caries remains the major oral health concern for older adults. ${ }^{10,11}$ Globally, dental caries is the most prevalent disease condition, affecting 2.4 billion people worldwide. ${ }^{12}$ Three age peaks are associated with dental caries: at 6, 25 and 70 years of age. ${ }^{12}$ Dental caries increment among frail older adults in LTC homes is more than twice that seen among those living in the community. ${ }^{13}$ In community-dwelling functionally independent older adults, there is a mean caries increment of one surface per year, similar to the incidence observed in people around the age of $25 .{ }^{11}$ Among those who suffer from dementia, the rate is twice as high. ${ }^{13}$ In the dental literature, there have been well-recognized worldwide trends towards decreasing tooth loss and increasing life expectancy, a trend labeled "demographic transition". ${ }^{11,12}$ Hence, the management of dental caries must continue to improve so patients can retain long-term function of their natural dentitions.

Untreated caries presents a biological, social, and financial burden to patients and their caregivers. ${ }^{12}$ The sequelae of inadequate dental care for caries may include acute episodes of pain, swelling, bleeding, and tooth loss. ${ }^{11}$ Untreated oral disease, which results in tooth loss, has 
numerous effects, including decreased chewing ability and nutritional intake, problems with speaking, diminished quality of life, avoidance of social interaction, and complications of other

chronic medical co-morbidities. ${ }^{7,11,14}$ Furthermore, there is an established association between poor dentition and systemic diseases, such as diabetes and cardiovascular disease, as well as a growing link between tooth loss/oral dysfunction and physical/cognitive deterioration in old age. ${ }^{14}$

There have been changes noted in the pattern of tooth loss worldwide. ${ }^{11}$ Historically, it was not uncommon for one to have all their teeth removed at a single time-point in their life. Now, it is more common to have incremental tooth loss over the course of a lifetime, owing to improved prevention, advances in operative dentistry, biomaterials, and changing patients' perceived value of their natural dentition. ${ }^{11}$ The concept of oral health related quality of life (OHRQoL) states that older people are not necessarily disabled by their accumulated burden of clinical oral disorders. ${ }^{11}$ Rather, age-associated stoicism, adaptability, capacity for coping, and an associated response shift mean most older adults manage reasonably well despite progressive tooth loss. ${ }^{11}$ Regardless, it has been suggested that OHRQoL is poorer amongst denture wearers, patients with high numbers of missing or decayed teeth, patients with dry mouth, and those with challenges with eating. ${ }^{11}$

\subsubsection{Provision of Dental Care in LTC Settings}

LTC facilities provide 24-hour professional supervision and medical care for patients with complex multimorbidity who can no longer be cared for in their own home or in assisted living. ${ }^{15}$ Services include basic accommodation, meals, clinical support services as identified in a care 
plan, ongoing social and recreational activities, specialized services (i.e. dementia or palliative care), and personal hygiene services. Previous studies have reported poor oral health and limited access to comprehensive dental care for frail older adults in LTC settings. ${ }^{8,16}$ Families and caregivers in LTC prefer dental services rendered within the facility itself, as it is more convenient. ${ }^{8,16}$ For those who access comprehensive dental services in LTC settings, objectively assessed oral health status has been reported to improve over 5 years ${ }^{17}$ Historically, numerous barriers have been encountered by dentists and other dental professionals providing care in LTC settings, including lack of equipment, limited treatment options, low financial return, and inadequate training in the management of complex patients with multimorbidity. ${ }^{7,16}$ For these reasons, dental care in Canadian LTC facilities has historically been limited to emergency treatment. ${ }^{16}$ To operate in LTC settings, dentists and affiliated dental personnel must also satisfy local health authority and facility-specific requirements to comply with hospital-grade standards of care and infection control. ${ }^{7}$ Others have also cited pressures from private practice and negative feelings associated with treating frail older patients as reasons to not provide care in LTC settings. "Ideal" dentistry, or an "academic" treatment plan, is difficult to render in LTC settings as there is chronic consumption of refined carbohydrates, cognitive limitations, behaviour management issues, and physical limitations in performing daily $\mathrm{OH}^{7} \mathrm{Up}$ to two-thirds of dentate LTC patients are reported to have untreated caries. ${ }^{18}$ These factors, which represent only a fraction of those affecting an older patient's risk for oral disease, are complex and require the prudent clinician to be innovative and adopt a practical, "rational" treatment plan that is individually tailored to the patient's goals and values. Nevertheless, previous authors stated that "no matter how appropriate dental treatment decisions may be, or how well restorations are placed, treatment outcomes of LTC facility residents are often compromised." 18 
Previously, three areas have been suggested as the focus of a comprehensive geriatric dental service in LTC settings: annual oral health assessment, access to dental treatment, and oral disease prevention. ${ }^{16,18}$ With the "demographic transition" previously discussed, there is an increasing demand for dental services for LTC residents, especially as patients become more dependent and retain more of their natural dentition. High levels of oral disease typically necessitate high levels of treatment need in this cohort. ${ }^{18}$ For example, one study reported that the mean incidence of new caries in LTC residents was 2.7 carious teeth per person over a 3-year follow-up. ${ }^{18}$ The scope of dental services required in LTC will also change in the future, with more older adults functioning with implant-supported and implant-retained restorations, which require specialized prosthodontic care. Certainly, an improved understanding of factors affecting the utilization of a dental service in LTC settings is useful, namely the impact of life expectancy, finances, and the perceived value of oral health. ${ }^{17}$

\subsubsection{CODE Index}

In the late 1990's, MacEntee \& Wyatt attempted to create a clinical index of clinical oral disorders in elders (CODE) ${ }^{19} \mathrm{CODE}$ is a multidimensional index, specific to elderly populations residing in LTC, which assesses jaw function, mucosal health, removable prostheses, teeth, and periodontium. Each category has weight-based criteria that combine to provide a composite score reflecting the overall clinical status of a frail older adult patient. It was originally suggested that CODE be combined with a psychosocial index to provide a thorough picture of the oral health of a frail older adult residing in LTC. Furthermore, CODE can be used to predict treatment need in a LTC patient cohort and can also be used to monitor the efficacy of dental 
care in this cohort when used in longitudinal analysis. The index provides a practical tool to score oral health and measure oral disorder in older adults, particularly those living in LTC.

The University of British Columbia (UBC) Geriatric Dentistry Program (GDP) has been utilizing CODE since its inception in 2002. Data collected from CODE examinations is stored on Microsoft Access databases. This database information is readily translatable to Microsoft Excel and SPSS for analysis.

CODE examinations involve clinical visual-tactile examinations and can be performed in a variety of settings. As many LTC homes do not have an on-site dental operatory or access to dental radiography, CODE exams are typically provided bedside or in a private room within the facility. The average length of an examination is nine minutes (range: 5 -14 minutes). ${ }^{19}$ The parameters examined include jaw function, maxillary and mandibular prostheses, mucosal disorders, tooth structures, and periodontium. A score of $0,1,2$, or 3 is provided to each parameter and combined to provide an overall CODE score: 1 reflects mild disease; 2 , moderate disease; and 3, severe disease. In MacEntee's original study, each component or disorder in the six categories received weights assigned through the consensus of thirty-three experienced dentists, prosthodontists, and dental hygienists. ${ }^{19}$ This weight-based scoring was found to have reasonable inter-rater reliability amongst these clinicians, with clinicians rendering the identical score to $85 \%$ of the disorders listed in the index. Intra and inter-examiner reliability was also found to range between $93-99 \%$ on repeated examinations. ${ }^{19}$ 
In the assessment of jaw function, the following parameters are assessed.

Table 1-1 Components of CODE Index Relating to Jaw Function ${ }^{19}$

\begin{tabular}{|l|l|}
\hline Components & CODE Score \\
\hline $\begin{array}{l}\text { Restricted Opening: }<30 \mathrm{~mm} \text { between incisors or }<45 \mathrm{~mm} \text { between residual } \\
\text { ridges at midline }\end{array}$ & 2 \\
\hline $\begin{array}{l}\text { Opening deviation: more than } 10 \mathrm{~mm} \text { from the midline on opening the mouth } \\
\text { at least } 20 \mathrm{~mm}\end{array}$ & 2 \\
\hline Temporomandibular or jaw muscle pain & 2 \\
\hline Occlusal attrition: $>2 / 3$ of $>$ half the dentition & 1 \\
\hline Temporomandibular Joint crepitation & 1 \\
\hline Less than two opposing molars or premolars bilaterally & 2 \\
\hline Acceptable & 0 \\
\hline
\end{tabular}

In the assessment of maxillary or mandibular removable prostheses, the following parameters are examined.

Table 1-2 Components of the CODE Index Relating to Maxillary/Mandibular Removable Prostheses ${ }^{19}$

\begin{tabular}{|l|l|}
\hline Components & CODE Score \\
\hline Use: Not worn or missing when a denture can be managed & 2 \\
\hline Quality (If worn) & 2 \\
\hline Stability: dislodged with light finger to a premolar & 2 \\
\hline $\begin{array}{l}\text { Retention: dislodged or loose when lips are licked with the mouth open } \\
\text { approx. 15mm }\end{array}$ & 2 \\
$\begin{array}{c}\text { Structure: missing parts, fractures, visible porosity, or other structural } \\
\text { defects }\end{array}$ & 2 \\
\hline Hygiene: calculus or visible plaque >50\% of denture base & 0 \\
\hline No Problems & 2 \\
\hline
\end{tabular}


In the assessment of mucosal disorders, the following elements are examined.

Table 1-3 Components of the CODE Index relating to Mucosal Disorders ${ }^{19}$

\begin{tabular}{|l|l|}
\hline Components & CODE Score \\
\hline $\begin{array}{l}\text { Extreme alveolar atrophy }(<1 \mathrm{~mm} \text { of attached mucosa facially or lingually } \\
\text { from the crest of the residual ridge along at least } 2 \mathrm{~cm} \text { of the alveolus) }\end{array}$ & 2 \\
\hline Ridge fibrosis ( $2 \mathrm{~mm}$ mobility along $>2 \mathrm{~cm}$ of the residual ridge) & 2 \\
\hline Angular cheilitis & 2 \\
\hline Stomatitis: generalized or papillomatous $(>1 \mathrm{sq} \mathrm{cm})$ & 2 \\
\hline Stomatitis: localized & 2 \\
\hline Denture induced hyperplasia (epulis) & 2 \\
\hline Mucosal pathoses & \\
\hline Glossitis & 3 \\
\hline White patch & 3 \\
\hline Pigmented patch & 3 \\
\hline Ulcer & 3 \\
\hline Abnormal lump & 3 \\
\hline Sinus or fistula & 3 \\
\hline Other urgent oral mucosal concerns & 3 \\
\hline None of the above & 0 \\
\hline
\end{tabular}

In the assessment of natural dentition, tooth structure and dental caries are assessed (Table 1-4). In assessing the status of teeth from a restorative standpoint, data from CODE can be used over time to assess caries status and tooth retention. This data can be combined over multiple years to estimate failure rates and/or survival rates of dental restorations. 
Table 1-4 Components of the CODE Index relating to Tooth Structures ${ }^{19}$

\begin{tabular}{|l|l|l|}
\hline Components & & CODE Score \\
\hline Tooth Structure & Missing posterior (non-aesthetic) & 0 \\
\hline & Missing anterior tooth (aesthetic) & 1 \\
\hline & Adequate fixed pontic & 0 \\
\hline & Adequate pontic on removable partial denture & 0 \\
\hline & Inadequate pontic & 2 \\
\hline & Intact tooth or tooth with adequate restoration & 0 \\
\hline Caries & Fractured tooth or restoration & 2 \\
\hline & Not obviously involving the pulp & 2 \\
\hline & Obviously involving the pulp & 3 \\
\hline
\end{tabular}

In the assessment of gingival health and the periodontium, the following parameters are examined.

Table 1-5 Components of the CODE Index relating to a Gingival Health and Periodontium ${ }^{19}$

\begin{tabular}{|l|l|}
\hline Components & CODE Score \\
\hline Missing tooth not to be replaced & 0 \\
\hline No gingival bleeding and $<5.5 \mathrm{~mm}$ pocket from free gingival margin & 0 \\
\hline Gingival bleeding and $<5.5 \mathrm{~mm}$ pocket (localized gingivitis) & 1 \\
\hline Calculus & 1 \\
\hline Pocket depth $>5.5 \mathrm{~mm}$ without purulent discharge & 2 \\
\hline Pocket depth $>5.5 \mathrm{~mm}$ with purulent discharge & 3 \\
\hline Vertically depressible (Class III mobility) & 3 \\
\hline
\end{tabular}

One shortcoming of the CODE index is that it does not provide a psychosocial perspective of the patient's self-perceived oral health. Certainly, this element is important for patients as it relates to their OHRQoL. However, the CODE index aims to objectively measure evidence-based, biologically justifiable clinical parameters, which most psychosocial indices related to oral health 
do not provide. ${ }^{19}$ Therefore, MacEntee suggested that the CODE index be combined with a psychosocial measurement to provide a robust overall view of oral dysfunction in older adults.

\subsubsection{Challenges in the Management of a Geriatric Dental Patient}

\subsubsection{Physical Frailty}

Older adults have more chronic diseases than younger cohorts. Providing dental care for older adults is complicated by the combined effect of multiple disease conditions. ${ }^{20}$ Common systemic diseases that directly impact the provision of dental care in geriatric patients include diabetes mellitus, cardiovascular diseases, hypertension, stroke, osteoarthritis (OA), and osteoporosis (OP). ${ }^{20}$ Dental treatment is adversely affected by these chronic diseases as well as the medications used to control them and their side effects. ${ }^{20}$ Polypharmacy due to multimorbidity is common amongst frail older adults and is highly relevant to dentistry due to many medications having anticholingeric side effects, specifically salivary hypofunction. ${ }^{21}$

Each of the common systemic conditions noted above, which contribute to physical frailty, have oral health implications. For example, diabetes has a well-established link with gingivitis and periodontal disease, with tooth loss being a recognized complication of diabetes. ${ }^{20}$ For patients with hypertension and cardiovascular diseases, medications used to treat these conditions have oral adverse effects, such as gingival hyperplasia, xerostomia, and mucosal lesions. ${ }^{20}$ In stroke and cerebrovascular disease patients, oral health implications include increased susceptibility to oral disease due to limitations in manual dexterity for $\mathrm{OH}$. These patients have challenges with inadequate $\mathrm{OH}$ and require aggressive prevention regimens. ${ }^{20}$ Osteoarthritis $(\mathrm{OA})$, when hands and wrists are involved, could also have oral health implications due to decreased manual 
dexterity. ${ }^{20}$ In a systematic review, oral health care was found to reduce the incidence of aspiration pneumonia in frail older adults at risk of aspiration pneumonia. ${ }^{10} \mathrm{~A}$ thorough review on systemic diseases, oral health implications, and modifications to dental care for patients with multimorbidity has previously been published. ${ }^{20}$

Polypharmacy is a critical element in the dental management of frail older adult patients as it can increases the incidence of adverse drug reactions and drug interactions. ${ }^{21}$ The number of drugs being taken has previously been shown to be a consistent risk factor for adverse drug reactions with the risk rising exponentially as the number of drugs increases. ${ }^{21}$ Both pharmacokinetics and pharmacodynamics are different in older adults due to the physiological effects of aging on end organ function and hence the susceptibility of older patients to medication effects, side-effects, and toxicity.

Another practical challenge in the dental management of frail older patients arises for those who are non-ambulatory. For these patients who are wheel-chair bound and cannot safely transfer from a wheel chair to the dental chair for treatment, patient transfer devices are necessary to safely and efficiently move a patient into a suitable operating position.

\subsubsection{Cognitive Decline}

Cognitive impairment is common amongst older adults and represents a substantial burden on society. In the US, more than $25 \%$ of older adults suffer from a broad spectrum of cognitive dysfunctions. ${ }^{22}$ Disorders that affect cognition have a direct influence on oral health, as declines in cognitive function lead to inadequate $\mathrm{OH}$. Inadequate daily oral self-care, such as brushing 
and flossing of teeth, increases risk of oral diseases. ${ }^{22}$ Frail older adults with cognitive impairment have increased rates of dental caries, increased denture sores, decreased denture use, and decreased salivary gland function. ${ }^{22}$ As previously mentioned, only a small proportion of older adults live in LTC, approximately $5 \%$ in Canada, while most older adults live independently in the community. ${ }^{22}$ For those patients transitioning from their own homes into LTC, oral problems tend to rapidly worsen as they settle into the new LTC living environment due to decreasing abilities to perform ADL and negative behavior changes. "Rapid Oral Health Deterioration" has been previously described in older adults. ${ }^{23}$ In a study of Australian older adults residing in LTC, oral care was found to be poor due to lack of staff training, time constraints on LTC staff, staff turnover, and that providing effective $\mathrm{OH}$ for another person is a difficult skill to master. ${ }^{13}$ To compound these challenges, the yearly retention of LTC staff in the US was reported to be approximately $50 \% .^{22}$

Diseases that affect cognition occur on a continuum, ranging from reversible cognitive impairment, to mild cognitive impairment, to dementia. ${ }^{22}$ Reversible cognitive impairments can be of neurologic or non-neurologic origin. Neurologic etiologies include neoplasms and normal pressure hydrocephalus where abnormal pressure is exerted onto neural tissues. Non-neurologic etiologies include vitamin deficiencies (usually vitamin B12), thyroid abnormalities, and neurosyphilis. ${ }^{22} \mathrm{~A}$ sudden change in mental status for an older adult without known cognitive issues is often due to delirium and not to dementia. Delirium can be a result of infection, electrolyte imbalances, dehydration, or the effects of polypharmacy. Older adults are more susceptible to delirium and delirium itself has been reported as a risk factor for Alzheimer's disease. ${ }^{22}$ Depression is also common amongst older adults, and this may be another cause for 
reversible cognitive impairment. ${ }^{22}$ Optimization of psychiatric illness is through cognitive behavioural therapy, pharmacotherapy, and consultation with psychiatry. ${ }^{22}$

Mild cognitive impairment (MCI) differs from dementia in that the patient experiences cognitive difficulties without significant decline in their ADL or impact on their quality of life. ${ }^{22} \mathrm{MCI}$ are classified into three categories: amnestic, non-amnestic, and of multiple domains. Amnestic MCI patients struggle with memory, while non-amnestic MCI patients struggle with executive functioning and aphasia. Patients with amnestic and multiple-domain MCI are at higher risk of developing Alzheimer's disease compared to their cognitively intact peers. ${ }^{22}$ Non-amnestic MCI patients do not appear to be at higher risk of developing Alzheimer's disease.

Dementia is defined as an irreversible cognitive impairment that presents with significant functional decline. ${ }^{22}$ Patients with dementia require significant help with ADL and IADL. ADLs are basic skills usually learned in early childhood, while IADLs are complex skills required to live independently, assuming one can perform ADLs.

Below is a list of ADL and IADL activities that can be compromised in dementia patients: ${ }^{22}$ 
Table 1-6 Activities of Daily Living and Instrumental Activities of Daily Living ${ }^{22}$

\begin{tabular}{|c|c|}
\hline $\begin{array}{l}\text { Activities of daily living (ADL) } \\
\text { - Skills usually acquired in early } \\
\text { childhood }\end{array}$ & $\begin{array}{ll}\text { - } & \text { Feeding } \\
\text { - } & \text { Toileting } \\
\text { - } & \text { Selecting proper attire } \\
\text { - } & \text { Grooming and brushing teeth } \\
\text { - } & \text { Maintaining continence } \\
\text { - } & \text { Putting on clothes and bathing }\end{array}$ \\
\hline $\begin{array}{l}\text { Instrumental activities of daily living (IADL) } \\
\text { - Complex skills required to live } \\
\text { independently }\end{array}$ & $\begin{array}{l}\text { - } \text { Managing finances } \\
\text { - Handling transportation (driving or } \\
\text { navigating public transit) } \\
\text { - Shopping } \\
\text { - } \text { Preparing meals } \\
\text { - Using telephone/communication } \\
\text { - device } \\
\text { - } \text { Managing medications } \\
\text { Basic housework/home maintenance }\end{array}$ \\
\hline
\end{tabular}

Four common types of dementia include Alzheimer's dementia, vascular dementia, dementia with Lewy Bodies, and frontotemporal dementia. Alzheimer's dementia is the most common and, for a small percentage of patients, there appears to be a genetic predisposition putting younger people at risk. ${ }^{22}$ Vascular dementia is the second most common, usually related to multiple cerebrovascular accidents which affect sensory, motor, and gait skills. ${ }^{22}$ Dementia with Lewy Bodies presents with Parkinsonian symptoms and cognitive impairment. ${ }^{22}$ Frontotemporal dementia is uncommon but presents at younger ages. ${ }^{22}$ Disinhibition is common, as are personality changes in these patients. Memory impairment is less prominent in frontotemporal dementia compared to other types of dementia. ${ }^{22}$

The oral biological effects of cognitive impairment on oral health are primarily related to inadequate $\mathrm{OH} .{ }^{22}$ Hence, modifications to dental care for the cognitively impaired patient should focus on comprehensive, individualized prevention regimens, such as diet, $\mathrm{OH}$ education, and 
patient-specific measures to increase tooth resistance to caries. ${ }^{22}$ Earlier intervention for these patients is typically easier as patients are more adaptable. ${ }^{22}$ As cognitive impairments continue, multiple factors come into play which affect treatment plans, including patient's personal $\mathrm{OH}$ skill level, interest in home care, social, financial, family, medical, ethical, and transportation/transfer issues. ${ }^{22} \mathrm{~A}$ focus on rational treatment plans that define achievable goals for each appointment and for home care provide a good foundation for management of these patients. The Canadian Dental Association Best Practices Guidelines on managing older adults suggests the same, as well as individualizing treatment plans to take into consideration patient's ability to handle stress and to consider alternative, reasonable treatments that are less extensive in patients with more advanced cognitive decline. ${ }^{24}$ The guidelines also encourage consideration of the patient's ability to maintain dental treatment. For example, in the frail older edentulous patient considering implant rehabilitation, one could consider removable implant prostheses instead of fixed implant prostheses, for ease of hygiene and future prosthetic repairs, if required.

\subsubsection{Social Factors and Other Barriers to Dental Care}

Numerous social factors also affect the provision of dental care for the frail older patient, including financial, legal, and ethical factors. ${ }^{22}$ These factors are important for communitydwelling older adults but are amplified for those residing in LTC due to their significant dependence on others and limited life expectancy. ${ }^{18}$ From a financial perspective, the cost of dental care is high for many people, given that many older adults are on fixed incomes or are impoverished. ${ }^{22}$ In Canada, dental care is privately funded or funded through dental insurance plans; however, many older adults are not covered after retirement and seek care on an emergent basis. ${ }^{8}$ To compound this, there have been dramatic increases in the retention of natural teeth. ${ }^{11,14}$ 
However, the dentition as a whole is usually heavily restored and the overall present and future treatment needs and costs will be greater than for previous generations. ${ }^{8}$ Furthermore, there have been changes to the fee schedules in some provinces for the management of medically frail patients residing in LTC, to reflect the increased time, complexity, and skill associated with their management. This change took place recently in British Columbia and is reflected in the BC Dental Association (BCDA) Dental Fee Guide.

An additional barrier to providing dental care is obtaining informed consent for dental treatment for LTC patients. ${ }^{84}$ Two issues that must be considered are consent for dental treatment plans and financial consent for treatment rendered. In Canada, there is a division in terms of providing consent for health care procedures and consent for funding of these procedures ${ }^{84}$ For the cognitively impaired patient who is unable to make medico-legal decisions, a personal representative under a representation agreement can make healthcare decisions for the patient, including dental treatment decisions ${ }^{84}$ Discussions regarding diagnosis, treatment, prognosis, and risks are to be directed at the personal representative. Other decision makers can also legally make health care decisions for a patient, including temporary substitute decision makers, personal guardians or committees, or public guardians and trustees. ${ }^{84}$

Payment for dental services, however, cannot be approved by a personal representative but must be through a power of attorney. The power of attorney has the responsibility of caring for the older adult's finances and legal affairs, including payment for dental services rendered ${ }^{84} \mathrm{In}$ many cases, the personal representative and the power of attorney is the same person, but this responsibility can also be split amongst multiple family members, such as adult children. ${ }^{84}$ 
Numerous other barriers to care for patients residing in LTC have also been reported, including gaps in oral health education of care staff, nursing accountability, poor promotion of oral health in LTC, and low professional engagement. ${ }^{25} \mathrm{~A}$ thorough review of these barriers and specific recommendations has been previously published. ${ }^{25}$ Effective and sustainable dental care in the LTC setting requires an interdisciplinary team of dentists, specialists, hygienists, assistants, LTC staff, and policy-makers. ${ }^{16,17}$

\subsubsection{Rational Treatment Planning for the Geriatric Patient}

The development of a treatment plan based on pre-operative and ongoing assessment of a patient's physical and cognitive status, alongside other factors previously discussed, is critical in the long-term management of the geriatric patient. In general, effective intervention for older adults is complicated by ageism, complex multimorbidity, poor access to age-appropriate care, finances, and inadequate income security and social protection. ${ }^{3}$ For most older adults who are community-dwelling and who are physically robust and cognitively intact, "conventional" treatment plans that optimize preventive health and appropriately use all sub-specialties of general dentistry, while aligning with patient values and goals, should be implemented. For community-dwelling older adults who are physically frail and/or have problems with cognition, "rational" treatment planning should be utilized and individualized to the patient and family. ${ }^{24}$ This requires careful evaluation of all risk factors, including, but not limited to, the patient's physical status and anticipated disease trajectory, cognitive status and anticipated trajectory, treatment needs and goals, environmental factors, and patient's OHRQoL. ${ }^{11}$ There is a difference in risk between community-dwelling older adults and those residing in LTC. Frail older adults 
living in LTC have more barriers to care and unique risk factors that render them more vulnerable to oral diseases compared to their community-dwelling counterparts. ${ }^{7}$ For frail older adults residing in LTC, the same 'rational' approach should be employed, with even further modifications that promote clinical pragmatism and optimize patient's quality of life. The focus for these patients should be elimination of odontogenic infection, control of oral inflammation, and maintenance of comfortable oral function. Certainly, "rational" dental care should be considered and discussed with the patient/family instead of 'technically idealized' care and this should take place in the context of understanding what an acceptable oral status is for any particular patient. ${ }^{26}$ The implementation of a 'rational' treatment plan that is practical and achievable should be discussed with decision makers in the treatment planning consultation.

In treatment planning restorative dentistry in older adults, multiple factors that affect the success, survival, and provision of dental restorations need to be considered. Patient's OH skill level, interest in home care, social, economic, family, medical, and transfer considerations play key roles as previously discussed..$^{22}$ However, several restorative dentistry factors are also important such as material properties, operative technique, operator skill level, occlusion, parafunction, and oral environment. For older adults, restorative dentistry should be conservative and focused on prevention. $^{27}$

In LTC settings, provision of restorative care is different than in the conventional dental operatory and should be modified to suit the needs of individual restorative dental appointments. This is guided by the "rational" dental care philosophy discussed earlier. ${ }^{26}$ Three modifications include the use of "Atraumatic Restorative Technique" (ART), patient positioning, and 
illumination. Previous studies have reported efficacy, cost-effectiveness, and improvement to patient's OHRQoL with techniques such as ART compared to conventional restorative techniques. ${ }^{28-30}$ The use of ART in patients with positioning issues can be beneficial, as restorative care can be provided bedside or in wheelchairs instead of in a traditional dental chair. For patients with cognitive decline or challenging behavior, ART can also be beneficial as there is a significant reduction in sensory stimulation compared to that induced by conventional rotary instrumentation. Specifically, the elimination of water spray, vibration, and sound from a rotary handpiece can aid behavior management in an uncooperative patient undergoing restorative care. ${ }^{29}$ Patient positioning is also a common issue encountered in the management of frail LTC patients, due to mobility/transfer challenges, wheelchair use, and problems with spinal curvature that limit visualization of the operative field. ${ }^{7}$ Many wheelchair-bound older adults have problems with spinal curvature, usually kyphosis, which require modification to facilitate operative care. The use of patient transfer devices, such as ceiling sling lifts or standing-andraising aids, should be routinely used by appropriately trained personnel to transfer patients to the dental chair to optimize safety. Pillows that adequately support the neck, lower back, and knees should be individualized to patients to improve patient comfort and support and help with the dental team's ergonomics. Appropriate illumination is also critical to providing restorative care. In the LTC setting, the use of a headlight is useful in the management of uncooperative patients who move their heads or those patients who have involuntary head, neck, or jaw movements as structures in the line of sight are always illuminated. ${ }^{7}$ 


\subsection{Direct Dental Restorations}

Dental restorations are used for the functional and aesthetic rehabilitation of lost tooth structure. In the following sections, different restorative materials and their properties, classification systems for restorative failures, evidence on restoration longevity, and the factors involved in restoration longevity will be reviewed.

\subsubsection{Selection of Direct Dental Restorative Materials}

Several materials have been traditionally used for direct dental restorations, including amalgam (AM), resin composite (RC), and glass ionomer cement (GIC). Each material has different physical, chemical, and mechanical properties, which affect their clinical performance. ${ }^{31}$ For geriatric patients, where larger restorations and root caries are prevalent, the selection of appropriate materials to restore chewing function and seal the tooth to prevent dental caries are important factors affecting restoration survival.

\subsubsection{Resin Composite}

Resin Composite (RC) has become the most widely used restorative material globally due to its many favourable properties and its ability to mimic tooth colour to create aesthetically pleasing restorations. ${ }^{31} \mathrm{RC}$ is a highly cross-linked polymeric matrix reinforced by a dispersion of glass, mineral, or resin filler particles and short fibers bound to the matrix by coupling agents. Other components of RC include photoinitiators and polymerization inhibitors. Photoinitiators, such as camphorquinone, work to convert RC from a soft paste into a durable restoration. Polymerization inhibitors work to extend storage life, which is especially useful for older types of RC which are 
chemically activated resins. ${ }^{31} \mathrm{UV}$ absorber molecules are also included to improve colour stability. ${ }^{31}$

Many different formulations of RC are available and are indicated for different clinical situations. These different formulations are created through selection of the filler size and content and dramatically impact the material's handling properties, viscosity, water sorption, radiopacity, and clinical performance (Table 1-7). ${ }^{31}$ Filler particles strengthen and support the RC matrix and aid with reduction of curing shrinkage and thermal expansion. ${ }^{31}$ Numerous different glassy fillers have been traditionally used, including the oxides of zirconium, strontium, barium, ytterbium, and quartz glass. ${ }^{31}$ Increased volume fraction filler improves mechanical properties, such as compressive and tensile strength, Young's modulus of elasticity, hardness, wear resistance, and fracture toughness. ${ }^{31}$ However, clinical studies have suggested that RC material properties have only a minor influence on its long-term survival and performance. ${ }^{32}$ Overall, the majority of RC available commercially perform well but hybrid RC have been suggested to be the gold standard for posterior restorations. Recent additions to the commercial market, including nano-filled RC, have been reported to be improvements over previous materials due to their higher polishability and luster at initial placement. ${ }^{32}$ However, it is unlikely they will outperform hybrid RC in long-term studies. ${ }^{32}$ 
Table 1-7 Classification of Composite Resins and Indications for use ${ }^{74}$

\begin{tabular}{|c|c|c|}
\hline Class of Composite & Particle Size & Clinical Use \\
\hline Traditional (large particle) & $1-50 \mu \mathrm{m}$ glass or silica & High-stress areas \\
\hline Hybrid (large particle) & $\begin{array}{l}1-20 \mu \mathrm{m} \text { glass } \\
40-\mathrm{nm} \text { silica }\end{array}$ & $\begin{array}{l}\text { High-stress areas requiring } \\
\text { improved polishability }\end{array}$ \\
\hline Hybrid (mid-filled) & $\begin{array}{l}0.1-10 \mu \mathrm{m} \text { glass } \\
40-\mathrm{nm} \text { silica }\end{array}$ & $\begin{array}{l}\text { High-stress areas requiring } \\
\text { improved polishability }\end{array}$ \\
\hline $\begin{array}{l}\text { Hybrid (minifilled/small } \\
\text { particle filled) }\end{array}$ & $\begin{array}{l}0.1-2 \mu \mathrm{m} \text { glass } \\
40-\mathrm{nm} \text { silica }\end{array}$ & $\begin{array}{l}\text { Moderate-stress requiring } \\
\text { optimal polishability }\end{array}$ \\
\hline Nanohybrid & $\begin{array}{l}0.1-2 \mu \mathrm{m} \text { glass or resin } \\
\text { microparticles }\end{array}$ & $\begin{array}{l}\text { Moderate-stress requiring } \\
\text { optimal polishability }\end{array}$ \\
\hline Packable hybrid & $\begin{array}{l}\text { Midfilled/minifilled hybrid } \\
\text { but with lower filler fraction }\end{array}$ & $\begin{array}{l}\text { Situations where improved } \\
\text { condensability is needed }\end{array}$ \\
\hline Flowable hybrid & $\begin{array}{l}\text { Midfilled hybrid with finer } \\
\text { particle sized distribution }\end{array}$ & $\begin{array}{l}\text { Situations where improved } \\
\text { flow is needed and/or where } \\
\text { access is difficult }\end{array}$ \\
\hline Homogenous microfilled & 40-nm silica & $\begin{array}{l}\text { Low-stress and subgingival } \\
\text { areas that require a high luster } \\
\text { and polish }\end{array}$ \\
\hline Heterogeneous microfilled & $\begin{array}{l}40 \mathrm{~nm} \text { silica } \\
\text { Prepolymerized resin } \\
\text { particles containing } 40 \mathrm{~nm} \\
\text { silica }\end{array}$ & $\begin{array}{l}\text { Low-stress and subgingival } \\
\text { areas where reduced } \\
\text { shrinkage is essential }\end{array}$ \\
\hline Nanofilled composites & $\begin{array}{l}\text { <100nm silica or zirconia } \\
\text { Homogeneous independent } \\
\text { nanoparticles or nanoclusters }\end{array}$ & $\begin{array}{l}\text { Anterior and noncontact } \\
\text { posterior areas }\end{array}$ \\
\hline
\end{tabular}

Most modern RC materials are light-activated. Photoinitiators present in RC, for example, camphorquinone, are typically activated by blue light at wavelengths around $468 \mathrm{~nm}$. This produces an excited state of the photoinitiator which causes free radicals to be formed and initiate an addition polymerization reaction. This 'command' setting of RC is one of its most desirable clinical characteristics. However, numerous factors affect the curing of RC, including curing lamp, depth of cure, and exposure time. ${ }^{31}$ Ultimately, these factors affect the degree of conversion, which has a direct influence on the clinical performance of the final restoration. ${ }^{31}$ Curing lamps must be selected that have a wavelength range encompassing the absorbance range 
of the photoinitiator used. Lamp tips must be placed as close as possible to the RC surface to optimize light intensity. Angle of the curing lamp tip should be perpendicular to the RC surface to deliver maximum intensity. ${ }^{31}$

Commonly cited reasons for failure of RC restorations include secondary caries, fracture, marginal deficiency, and wear. ${ }^{31}$ Clinical placement of RC restorations requires excellent moisture control as contamination of dentin or enamel bonding surfaces with saliva, gingival

crevicular fluid, or blood negatively affects the ability to create a uniform hybrid layer. ${ }^{31,35}$ Indeed, previous systematic reviews have reported that adhesive systems play an important role in RC longevity, with three-step etch-and-rinse and two-step self-etching systems outperforming one-step systems. ${ }^{32,33}$ Clinically, moisture control is best achieved with rubber dam isolation. The bonding ability of bonding systems differs between enamel and dentin, with superior bonding possible to enamel surfaces. ${ }^{31,35}$ Achieving a reliable bond to dentin or cementum has been an ongoing problem for RC restorations and is a commonly cited reason for secondary caries, notably at the gingival margin of a class II restoration. ${ }^{27}$ In geriatrics, this is a significant concern as many restorative margins are predominantly on dentin or cementum margins due to the prevalence of root caries. ${ }^{27}$

\subsubsection{Glass Ionomer Cement}

Glass ionomer cement (GIC) is a material used for many dental applications, including restoring non-carious cervical lesions, root caries, ART, and long-term provisional restorations in multisurface cavities. ${ }^{27,31} \mathrm{GIC}$ have several desirable properties, including excellent adhesion, marginal sealing, biocompatibility, fluoride release, as well as good anti-cariogenic and 
mechanical properties. ${ }^{27,31}$ Furthermore, it is tooth-coloured and has minimal dimensional change. ${ }^{27}$ For the geriatric dental patient, these properties are highly favourable and GIC have previously been implicated as an ideal restorative material. ${ }^{27,34}$

GIC is based on a reaction between an acid soluble fluoraluminosilicate glass powder and polyalkenoic acids. ${ }^{31}$ The liquid polyalkenoic acid component consists of a copolymer of acrylic, maleic, and itaconic acids. ${ }^{31}$ The bonding mechanism between GIC and tooth structure is via chelation of $\mathrm{Ca}^{2+}$ present in enamel and dentin by carboxyl groups in the material. ${ }^{31}$ This has been found to be a stable and durable bond. ${ }^{31} \mathrm{GIC}$ materials can be classified in two separate ways- by composition or based on indication. Classification based on composition states that there are four groups of GIC- conventional, metal-reinforced, resin-modified, and high viscosity. Classification based on indication splits GI into three categories- as either a lining, restorative, or luting material. ${ }^{31}$

A material commonly used in geriatric patients, especially with ART, is Fuji IX from GC America, which is a high viscosity, Type IIb (reinforced restorative cement) GIC. High viscosity GIC have smaller glass particles, greater powder-liquid ratios, which improve mechanical properties, and have excellent packability. ${ }^{31}$ Resin-modified GIC (RMGIC), such as Fuji II LC, is different in chemical composition, with $20-30 \%$ of its composition being resin components. ${ }^{31}$ Its powder component is fluoraluminosilicate glass with photoinitiators, such as camphorquinone, while the liquid component is polyacrylic acid, HEMA, and polyacrylic acid modified with methacrylate. ${ }^{31}$ RMGIC materials have improved mechanical properties, extended working time, controlled cure, improved translucency and aesthetics compared to conventional 
GI. ${ }^{31}$ Regardless of the type of GIC, the material must be protected from water sorption for the first 24 hours after placement as structural changes are induced by variation in the moisture content of newly set GI. ${ }^{31}$ This is typically accomplished with a light-cured resin varnish. ${ }^{31}$

The benefits of GIC materials include adhesiveness, biocompatibility, fluoride release, marginal sealing, radiopacity, and coefficients of thermal expansion similar to enamel/dentin. ${ }^{31}$ With regards to adhesion, GIC chemically bonds to tooth structure as well as engages enamel and dentin through micromechanical bonding. In one study, GIC was found to have better bonding over time compared to 1, 2, and 3-step etch and rinse RC. ${ }^{35}$ GIC's biocompatibility is good, with minimal detriment to pulpal cells if a minimum of $0.5 \mathrm{~mm}$ of dentin remains between the material and pulp. ${ }^{85}$ Fluoride release is a key feature of GI materials, with highest fluoride release taking place in the first 48 hours. ${ }^{31}$ Some have reported a caries-inhibitory effect over time as the material acts as a fluoride reservoir. ${ }^{31,36}$ Previous studies have shown that incipient carious lesions adjacent to GI restorations exhibit hypermineralization compared to caries adjacent to other restorative materials. ${ }^{36}$ Long-term release of fluoride from GI materials depends on these oral fluoride reservoirs being replenished by fluoridated toothpastes or clinical applications of topical fluoride. ${ }^{31}$ However, the cariostatic properties of GI have been debated and several studies conflict as to whether GI materials clinically prevent or inhibit secondary caries lesions compared to non-fluoridated restorative materials. ${ }^{31,36}$ Indeed, some studies suggest that while fluoride release may be high initially, the amount of fluoride release decreases substantially to a level that may not be clinically relevant. ${ }^{36}$ Limitations of GIC include poor mechanical properties, solubility, and inferior aesthetics compared to RC. 
In geriatrics, GIC has earned its place as a restorative material option due to its many sound biomaterial properties, but another practical benefit is its ease of clinical application. ${ }^{27,34}$ Its ability to be quickly inserted through automix capsules and finished primarily with hand instrumentation make it clinically useful when compared to clinical procedures required for AM or RC restorations. ${ }^{34}$ Its ability to tolerate some moisture is also desirable, as many restorative situations in geriatrics involve sub-optimal hemostasis and moisture control. In contrast, RC requires excellent moisture control, with previous concerns at the gingival margin of deep restorations and the ability to create a predictable micromechanical seal. ${ }^{27} \mathrm{Hence}, \mathrm{RC}$ should be considered primarily for the low-caries risk patient with good $\mathrm{OH}$.

\subsubsection{Clinical Assessment of Restorations in Dental Research}

Several clinical evaluation guidelines for the assessment of dental restorations have been previously used, including the Ryge criteria, US Public Health Service (USPHS) criteria, and the FDI criteria. ${ }^{37,38}$ It is advantageous to have uniformity in the clinical assessment of direct dental restorations to facilitate comparison of prospective studies in different populations. High-quality prospective studies use multiple calibrated examiners that are blinded to patient/restorations being evaluated.

In the Ryge criteria, restorations are assessed on retention, colour match, marginal discolouration, secondary caries, marginal adaptation, surface texture, and anatomic form. ${ }^{39}$ Three grading categories exist for each criterion. The Ryge or modified Ryge criteria were commonly used in restoration longevity research in the 1980-1990's. The USPHS criteria are also commonly used in assessments of dental restoration longevity and have been modified over 
the years for different studies assessing restoration longevity/quality. They are similar to the Ryge criteria, with the addition of a category for post-operative sensitivity. ${ }^{40}$ The most comprehensive criteria used to asses direct or indirect dental restorations for prospective studies was published by FDI World Dental Federation in $2010 .{ }^{38}$ In these criteria, three overall properties are to be assessed by several calibrated/blinded examiners. These include esthetic, functional, and biological properties. Within each property, several criteria are assessed. Under esthetics, examiners grade surface luster, surface staining and margin, colour match and translucency, and esthetic anatomical form. Under functional properties, examiners grade fracture of material and retention, marginal adaptation, occlusal contour and wear, approximal anatomic form (contact point and contour), radiographic examination, and patient view. Under biological properties, examiners grade post-operative sensitivity and tooth vitality, recurrent caries/erosion/abfraction, tooth integrity/cracks/fracture, periodontal response, adjacent mucosa, and oral/general health. Each criterion has five possible scores ranging from clinically poor to clinically very good. An overall esthetic, functional, and biological score is provided at the end. ${ }^{38}$ For dental researchers, a web-based training and calibration tool was created, named "e-calib", and has been recommended for future prospective studies on restoration longevity. ${ }^{38}$

The difference between dental restoration success and survival is an important distinction; the above clinical evaluation criteria are barometers of restoration success. In retrospective studies, it is not possible to perform calibrated and blinded clinical gradings of restorations; therefore, retrospective research on restoration longevity typically assesses restoration survival. In several retrospective studies, investigators have used re-restoration, endodontic treatment, and extraction as "events" to measure restoration survival times and compute annual failure rates. ${ }^{41,42}$ This is a 
clinically relevant statistic as true failures necessitate subsequent operative or surgical treatment. Indeed, several authors have noted that while randomized control trials (RCT) provide a high level of evidence for hypothesis testing, long-term RCTs to assess restoration longevity are scarce and may not reflect the survival of restorations in general dental practice..$^{43-45}$ Investigating re-intervention rates or need for subsequent treatment for previously placed restorations is highly relevant to general dental practice.

No clinical evaluation criteria for dental restorations have been identified specific to a geriatric cohort. In LTC settings, restoration survival is likely more relevant than restoration success as an evaluation criterion as the goal of providing restorative care is to minimize morbidity and future invasive procedural appointments. ${ }^{27,34}$ For most patients in this cohort, functional and biological success supersedes esthetic requirements. ${ }^{34}$

\subsubsection{Conventional and Atraumatic Restorative Technique}

Several authors have previously discussed provision of dental restorations in LTC settings through conventional or alternate means. After the introduction of consistently effective local anesthesia in the $20^{\text {th }}$ century, tooth preparation by conventional high and slow-speed rotary handpieces has been the mainstay in operative dentistry. However, for patients living in developing areas of the world, or who face other barriers to dentistry, the use of ART has been suggested. ${ }^{46}$ Specifically, the use of ART in a LTC setting has shown clinical longevity, costeffectiveness, and improved patient's perceived oral health status. ${ }^{28,29,46}$ A two-year study reported that the survival of ART restorations was the same as those provided through conventional means. ${ }^{29}$ Another study reported an $80 \%$ five-year survival of ART restorations in 
permanent teeth. ${ }^{47}$ In a study of community-dwelling elders, patient's perceived oral health was improved with ART. ${ }^{29}$ Another study from Hong Kong investigating ART longevity in root caries lesions in community-dwelling older adults reported no statistical difference between ART and conventional restorations over 12 months. ${ }^{48}$ Most of the restorations from this study were single surface cervical lesions and the 12-month survival was reported at roughly $90 \%$ for both groups, though the sample size was small. ${ }^{48}$ Furthermore, in a study conducted among LTC patients, ART was found to be more cost-effective than conventional treatment and care could be provided at facilities without a conventional dental clinic. ${ }^{28}$ ART has also been used in healthy adult populations with reasonable longevity. A 6-year evaluation looked at the longevity of ART restorations in Class III lesions in permanent anterior teeth. ART was suggested to be acceptable for permanent class III restorations as they reported a $70 \%$ survival rate at six years, although the sample size was also small in this study. ${ }^{49}$

ART comprises of hand instrumentation of open carious lesions followed by placement of a restorative material, usually GIC, without the need for local anesthesia. Treatment is typically carried out under cotton roll isolation and does not require high or slow-speed instrumentation. ${ }^{34}$ In the LTC setting, numerous clinical situations requiring restorative dental care exist where ART could be an appropriate treatment modality. For example, in patients with advanced dementia who are uncooperative for dental care, use of ART to treat cervical root caries lesions on easily accessible buccal surfaces is a safe and effective way to manage caries and negates the need for high-speed handpieces with water/air spray and high-volume suction. The decreased sensory stimulation associated with ART (i.e. sound/water spray/vibration from high/slow-speed 
handpiece; sound/suction from high-volume suction) likely optimizes a clinician's ability to provide restorative care in uncooperative patients. ${ }^{27}$

\subsubsection{Restoration Longevity}

Reasons for dental restoration failure fall into four categories: primary reasons, secondary reasons, pulpal inflammation and infection, and esthetics. ${ }^{40}$ Primary reasons include caries, tooth fracture, cracks, attrition, erosion, abrasion, and abfraction lesions. Secondary reasons include replacement of old restorations, loss of retention, or restoration fractures. Pulpal problems include pulp exposure, hypersensitivity, and pulpal pain. Esthetics reasons include diastema closures and discolouration of old restorations. ${ }^{40}$ The longevity of direct restorations is an important consideration as much of the work for general dentists is the placement and replacement of restorations. ${ }^{50}$ Four factors have previously been implicated in the longevity of dental restorations. These include patient factors, operator factors, caries risk, and parafunctional habits. ${ }^{43,51-53}$ For example, type of restorative material, increasing number of surfaces involved in the restoration, previous endodontic treatment, socioeconomic status, and age were associated with restoration longevity. ${ }^{50}$ Other factors such as operator skill, placement technique, criteria for replacement, patient compliance with $\mathrm{OH}$, and the oral environment and its contribution to patient's caries risk have also been implicated. ${ }^{54}$

Previous studies investigating restoration longevity have been limited to private practice-based research or dependent upon insurance or government health databases and have mostly been performed in healthy pediatric and adult populations. ${ }^{50,51,55-57}$ In the following sections, the 
literature on restoration longevity in three age cohorts- adult, pediatric, and geriatric- will be reviewed.

\subsubsection{Adult Populations}

In adult populations, past studies assessing restoration longevity have primarily been retrospective analyses from insurance records, isolated dental practices, public health databases, dental school populations, and Navy/Army cohorts. ${ }^{50,51,55,56}$ Overall, direct dental restorations were deemed to be successful and have reasonable longevity in healthy adult patients. Restoration longevity is affected by multiple factors, including patient, dentist, and material factors. ${ }^{39,40}$ Tooth-specific parameters, such as tooth location, cavity size, and cavity type also affect restoration longevity. ${ }^{58}$ Some general trends noted in the literature across different populations of healthy adults include higher hazard ratios for RC compared to AM, high caries risk compared to low caries risk, molars compared to premolars or anterior teeth, and multisurface restorations compared to single-surface ones. ${ }^{40,42,59}$

AM restorations have generally been reported to outperform RC and GIC restorations with respect to long-term survival, but not to clinical performance. ${ }^{42,44,54,56,59-62}$ In a large retrospective study using the UK Dental Practice Board Database of over 500,000 restorations placed in approximately 80,000 patients, the average age of restorations was 7.1 years and amalgam restorations were noted to last longer than RC or GIC restorations. ${ }^{51,54}$ In a recently published study from the University of Manitoba, a total of 2,820 AM and RC restorations placed in premolars by dental students were followed and a 12-year survival estimate of $91.5 \%$ was reported for AM and $86 \%$ for $\mathrm{RC} .{ }^{41}$ In a cross-sectional Finnish study, the median survival of 
AM was reported at 15 years, while RC and GIC survival was reported at 6 and 7 years, respectively. ${ }^{60}$ Similar figures have also been reported in other healthy adult populations with median AM survival at 12.8 years and median RC survival at 7.8 years. ${ }^{63}$ Median survival time is defined as the time that a restoration would have a $50 \%$ chance of surviving. ${ }^{64}$ Older studies have reported that $\mathrm{RC}$ has an annual failure rate (AFR) of up to $13 \%$ compared to AM which has an AFR less than $5 \%$; in other terms, RC fails 2-3 times the rate of AM. ${ }^{65}$ Secondary caries is commonly cited as the reason for RC failures and their risk is higher compared to AM. ${ }^{45,66}$ It is important to recognize that older studies conducted in the late 1990's and early 2000's were limited by early RC technology and techniques and that advances in this technology have changed the clinical performance and longevity of RC materials. ${ }^{64}$ A more recent study comparing AM and RC longevity was conducted in young men in the US Navy and stated that there was no difference in hazard ratio with respect to rates of replacement. ${ }^{67}$ Indeed, a 2017 retrospective study measuring survival of posterior $\mathrm{RC}$ restorations placed by one motivated provider in healthy adult patients under rubber dam isolation reported a median survival time of 11 years and 7 months. ${ }^{33}$ As with other studies, premolars were reported to out-perform molars with respect to survival.

With declining global use of AM, several meta-analyses and more recent studies have shown that $\mathrm{RC}$ has reasonable longevity and its routine use as a restorative material is justified. A Toronto meta-analysis which included 16 studies with a minimum follow-up period of 3 years concluded that $\mathrm{RC}$ is an appropriate posterior restorative material. ${ }^{68} \mathrm{~A}$ more recent review conducted on long-term RC longevity identified 34 papers with a minimum 5-year follow-up, which included prospective and retrospective clinical studies as well as longevity studies utilizing secondary 
data. ${ }^{32}$ Overall, these studies reported that the AFR of RC in vital teeth ranged from $1 \%$ to $3 \%$ and the AFR of RC in endodontically treated teeth ranged from $2 \%$ to $12.4 \% .{ }^{32}$ The longevity of $\mathrm{RC}$ has also been reported to be equivocal to AM over 10 years, although this study suggested AM to be a more appropriate choice for high caries risk patients. ${ }^{53,62}$ In this study, AM survival was reported at $79.2 \%$ and $\mathrm{RC}$ at $82.2 \%$ over 10 years. ${ }^{62} \mathrm{~A}$ recent meta-analysis of 12 studies of at least 5-year follow up by the same author reported the five-year AFR for RC at $1.8 \%$ and the 10-year AFR at $2.4 \% .{ }^{55}$ Multivariate Cox regression from this study showed that with every extra surface added to a restoration, there was a $30-40 \%$ increased risk for failure. ${ }^{55}$ Previous AFRs reported for RC also ranged between $1-3 \% .^{39,58,69}$

Fewer studies have been conducted to compare the longevity between RC and GIC restorations. The bulk of studies have reported that retention of GIC was superior to RC, but that the mechanical properties of RC were superior. ${ }^{70-73}$ In a systematic review and meta-analysis of 19 articles, GIC restorations in non-carious cervical lesions (NCCL) were concluded to have superior retention compared to $\mathrm{RC} .{ }^{73}$ In NCCL, there are several different bonding surfaces, including cut and uncut enamel, hypermineralized surface layer of dentin, additional bacterial layers, and cementum. The authors suggested that GIC has better retention in these lesions as highly mineralized sclerotic dentin is amenable to chemical bonding via calcium. The evidence, however, was graded as low-moderate in this study. A recent retrospective Korean study comparing GIC and RC with Cox proportional hazards modelling reported that there was no statistical difference in longevity between the two materials. ${ }^{72}$ As with other studies, RC was stated as having superior clinical properties with respect to function and aesthetics. In covariate analysis in a Cox proportional hazards model, no differences were noted between the two 
materials with regards to secondary caries, wear, or hypersensitivity. ${ }^{72}$ Also, this study and others have purported that fluoride release from GIC materials is not a clinically relevant feature of the material as it does not sustain sufficient in vivo levels to prevent secondary caries. ${ }^{72,73}$

Covariate analysis in restoration longevity research helps to guide treatment recommendations and techniques. In a Japanese study from 2007, healthy, compliant adults were followed over 19 years to assess restoration longevity, tooth survival, and the effect size of confounding variables through a Cox proportional hazards regression models. Unrestored teeth were found to have the best overall tooth survival. ${ }^{74}$ Restorations with 3-5 surfaces were four times more likely to fail and be extracted than unrestored teeth. ${ }^{50,74}$ Crowns and bridge abutments had fewer restorative failures compared to complex multi-surface restorations. ${ }^{74}$ Teeth used as abutments for removable prostheses had higher failure rates compared to other teeth. ${ }^{74}$ Similar results were also reported in a cross-sectional Korean study. In this study, it was further reported that teens and older adults over 70 years were at higher risk of restoration failure than healthy adults and that females were at a lower risk than their male counterparts (Relative risk $=0.65$ ). ${ }^{40,42}$ These results mirror those from a large UK study that found that restorations placed in older adults and teens had lower survival compared to healthy adults. ${ }^{51}$ Burke reported that the highest AFR was in the oldest age cohort in their study. ${ }^{51}$ There is some controversy in the literature regarding the effect of patient age on restoration longevity, as some authors have argued that age does not have an impact. ${ }^{43}$ Tooth type also influences restoration longevity. Molars had a relative risk (RR) of 2.45 compared to pre-molars and Class II restorations were 1.63 times more likely to fail compared to Class I restorations. ${ }^{42}$ This study also reported that $\mathrm{RC}$ had a RR of 2.28 compared to AM but that its clinical performance was not different. There appears to be no difference in 
restoration longevity in the presence of controlled systemic disease in healthy adults. ${ }^{40}$ Pin placement or endodontic treatment also has a negative effect on restoration longevity. ${ }^{51}$

\subsubsection{Pediatric Populations}

Numerous studies of dental restoration longevity in pediatric populations have reflected trends seen in healthy adult populations. Several, large randomized control trials assessing restoration longevity in healthy pediatric cohorts have reported superior longevity of AM compared to RC restorations, although some results were not statistically significant. In these studies, RC restorations were reported to have a higher risk for recurrent caries $(\mathrm{RR}=3.5)$ as compared to AM. ${ }^{61}$ The survival rate for AM in this study was reported at $94.4 \%$ and that of RC at $85.5 \%$ over a 7-year follow-up. This translates to an AFR of 0.16-2.83\% for AM and an AFR of 0.94$9.43 \%$ for RC. ${ }^{61}$ As in adult populations, multi-surface restorations required more frequent replacement as compared to smaller restorations. ${ }^{75}$ The most common reason for restoration replacement was dental caries adjacent to the restoration.

There have been several pediatric studies investigating the longevity of GIC restorations.

Overall, GIC has proven to be a durable restoration in the primary dentition. Compared to AM, GIC was reported to be equivalent in a 2-year follow-up in primary molars. ${ }^{47}$ GIC has mostly been used with ART and has been reported to have a high caries preventive effect. In permanent molars of young children, the 5-year survival rate of GIC restorations was reported at $80 \% .{ }^{47}$

In a prospective study of Northern European teenagers from the early 2000's, AFR of RC were again reported to be higher than AM. In this cohort, the AFR for RC was $2.9 \%$ and $1.6 \%$ for 
AM. ${ }^{56}$ Teenagers, as a group, are known to be at higher risk of caries, and have been compared to other caries-susceptible groups such as very young children and older adults..$^{40,63}$

\subsubsection{Geriatric and Special Populations}

Compared to adult and pediatric studies, there is limited research on restoration longevity in geriatric populations. In one large study of over 500,000 restorations from the UK Dental Practice Board database, sub-analysis was performed and reported on restoration longevity in adults older than 70 years. This study utilized re-intervention dates as a surrogate measure of restoration longevity, due to its large sample size and retrospective nature. In this sample of approximately 30,000 adults older than 70 years at 5-year follow-up, overall survival for all materials (AM, RC, GIC) was reported at $49 \% .^{51}$

A recently published study from the University of Iowa was the first to specifically report on dental restoration longevity in a functionally-independent, community-dwelling geriatric population. Over 1,500 patients, representing 9,184 individual restorations, were recruited from the outpatient Geriatric and Special Needs clinic at the University of Iowa. In this large, retrospective study, restorations were followed over 15 years until they incurred an event (i.e. rerestoration, extraction, endodontic treatment) or were censored. In their follow-up period, $28.7 \%$

of restorations incurred an event and the median survival was reported at 6.2 years. ${ }^{76}$ As with previously published results, Cox multivariable regression models reported RC and multi-surface restorations as having higher risk of failure. Restorations that were the first to be placed in a tooth also had greater longevity than restoration replacements. Another study from the 
University of North Carolina reported that presence of caries and the use of a removable prosthesis synergistically compromise tooth survival in older patients. ${ }^{14}$

There has been some research reporting on special patient populations, such as head and neck cancer patients who have undergone radiation therapy ${ }^{77}$ These patients are at very high risk of caries due to salivary gland hypofunction if major salivary glands are in the field of radiation therapy. In a small sample of 15 cancer patients, ART was reported to have equivocal longevity to conventional treatment, with a 2-year survival rate of $65 \%$. The pattern of decay in these patients typically results in multi-surface cervical lesions that are extremely challenging to restore and are not unlike those seen in geriatric patients.

The longevity of GIC restorations has also been studied in geriatric cohorts, mostly in studies assessing the efficacy of ART. In one small study of community dwelling older adults, ART restorations restored with GIC were followed for 12 months and $68 \%$ were reported to be acceptable. ${ }^{78}$ In a 6-month study of restoration longevity in LTC residents, ART was compared to conventional treatment and the survival of ART restorations was reported at $81 \%$ and conventional treatment at $92.9 \% .{ }^{46}$ ART with GIC has been a technique encouraged for patient cohorts that do not have adequate access to a conventional dental clinic setting. In a 2-year follow-up comparing the survival of ART restorations and those placed using conventional methods, no statistically significant difference was found. The 2-year survival for these two groups was reported between $85-90 \% .{ }^{29}$ Furthermore, ART has been reported as cost effective treatment option, specifically in LTC residents. ${ }^{28}$ 
The longevity of direct dental restorations in frail elderly patients living in LTC homes is likely different than in other cohorts due to several reasons. This cohort of patients is typically frail in terms of physical and cognitive status, has medication-related hyposalivation, decreased mobility, and increased barriers to oral health care. ${ }^{79}$ Furthermore, dental carious lesions in the geriatric population present challenging clinical scenarios due to their extent and location. Root caries in difficult-to-treat locations, circumferential cervical decay resembling radiation caries, and extensive recurrent decay around fixed prostheses. Due to decreased ability to perform selfcare, $\mathrm{OH}$ is typically poor in these patients. ${ }^{17}$ Therefore, there are important patient factors negatively influencing the longevity of direct dental restorations in this cohort compared to other populations.

\subsubsection{Factors Affecting Restoration Longevity}

Numerous factors influence the ultimate longevity of dental restorations. Optimizing the factors that are within the control of the dentist and patient is essential to ensuring durable, long-lasting restorations that provide years of acceptable service to the patient. ${ }^{39}$ In the following sections, the factors affecting healthy adult and geriatric populations will be explored.

\subsubsection{Healthy Populations}

Factors affecting restoration longevity can be categorized as patient, dentist, and material factors (Table 1-8). Patient factors include $\mathrm{OH}$, dietary behaviours, preventive measures, recall compliance, oral environment, systemic diseases, cavity-specific parameters (i.e. size, shape, location of lesion; vital vs. non-vital; molar vs. pre-molar), cooperation during treatment, and parafunctional habits. ${ }^{39}$ Dentist factors include optimal cavity preparation and operative 
techniques. ${ }^{39}$ Material factors include biomaterial characteristics such as fracture strength, fatigue, wear resistance, bond strengths, and caries inhibiting effects. ${ }^{39}$ Thus, numerous factors are at play influencing the longevity of a dental restoration but can be optimized by an appreciation of the above-mentioned categories.

Table 1-8 Factors Influencing the Longevity of Dental Restorations ${ }^{40}$

\begin{tabular}{|l|l|l|}
\hline Patient & $\underline{\text { Dentist }}$ & Material \\
\hline Oral hygiene, Dietary habits & Correct indications & Strength (fractures) \\
\hline $\begin{array}{l}\text { Preventive measures, fluoride } \\
\text { availability }\end{array}$ & $\begin{array}{l}\text { Cavity preparation (size, type, } \\
\text { finishing) }\end{array}$ & Fatigue/degradation \\
\hline Compliance in recall & Handling and application & $\begin{array}{l}\text { Wear resistance (occlusal } \\
\text { contact areas, contact-free } \\
\text { areas) }\end{array}$ \\
\hline $\begin{array}{l}\text { Oral Environment (quality of } \\
\text { tooth structure, saliva, etc.) } \\
\text { and systemic disease }\end{array}$ & $\begin{array}{l}\text { Curing mode (device, time, } \\
\text { light intensity) }\end{array}$ & $\begin{array}{l}\text { Bond strength, } \\
\text { polymerization shrinkage, } \\
\text { post-operative sensitivity }\end{array}$ \\
\hline $\begin{array}{l}\text { Size, shape, location of the } \\
\text { lesion and tooth (number of } \\
\text { surfaces, vital vs non-vital } \\
\text { tooth, premolar vs molar) }\end{array}$ & $\begin{array}{l}\text { Mode of finishing and } \\
\text { polishing of the restoration }\end{array}$ & $\begin{array}{l}\text { Chemical compatibility of } \\
\text { restorative systems }\end{array}$ \\
\hline Cooperation during treatment & Correct occlusion & Technique sensitivity \\
\hline $\begin{array}{l}\text { Bruxism/parafunctional } \\
\text { habits }\end{array}$ & $\begin{array}{l}\text { Experience (with material and } \\
\text { restorative technique) }\end{array}$ & $\begin{array}{l}\text { Caries inhibiting effects } \\
\text { (release of fluoride) }\end{array}$ \\
\hline
\end{tabular}

Previous studies conducted by Burke reported greater longevity for teeth with smaller restorations compared to multi-surface restorations, AM compared to tooth-coloured restorative materials, and for teeth without pin placement or endodontic treatment. ${ }^{54}$ In this retrospective study, which had a sample size of over 500,000 restorations, one surface AM restorations were found to have the longest survival (10-year survival= $58 \%)$ compared to larger, multi-surface AM and tooth-coloured restorations. ${ }^{51}$ Other studies reported that removable prosthesis use was 
associated with 2.4 times higher rates of caries (Multivariate $\mathrm{OR}(\mathrm{CI})=2.4(1.5-4.1), \mathrm{p}<0.01) .{ }^{80}$ This Danish study also reported a significant effect of tobacco use on active root caries, with $40 \%$ lower risk of root caries in patients who had never smoked (Multivariate OR $(\mathrm{CI})=0.4(0.3$ 0.6), $\mathrm{p}<0.001)$. Removable prosthesis use and caries have also been reported to synergistically increase tooth loss. ${ }^{14}$

Other studies have investigated the effect size of several covariates on restoration longevity through a Cox multi-variable regression and identified that high occlusal stresses and high caries risk, when combined, yield a hazard ratio of $8 .{ }^{43}$ Furthermore, mandibular teeth, molars, and non-vital teeth were also associated with increased hazard ratios. ${ }^{43}$ Other studies have also used Cox multivariable regression models to measure the effect size of covariates on restoration longevity. In a Korean study, tooth type, age group, cavity classification, indication for restorative treatment, materials, gender, and operator were identified in multivariate Cox proportional hazards model to significantly influence restoration survival $(\mathrm{p}<0.05) .{ }^{40}$ Specifically, healthy adults between 40-50 years have a 0.39 lower likelihood of restoration failure compared to teenagers $(\mathrm{p}=0.015)$, molars have a 2.13 higher likelihood of failure compared to incisors $(\mathrm{p}<0.001)$, Class II restorations are at 1.52 higher likelihood of failure compared to Class I restorations $(\mathrm{p}=0.020)$, and females are at 0.73 lower risk of restoration failure compared to men $(\mathrm{p}=0.008) .{ }^{40}$ These findings have been repeated in other studies. ${ }^{42}$ In Rho's study, adults aged 50-60 were reported to be 0.37 lower risk for restoration failure compared to teenagers $(\mathrm{p}=0.010)$, restorations using $\mathrm{RC}$ were at 2.28 higher risk than AM $(\mathrm{p}<0.001)$, molars were at 2.45 higher risk compared to premolars $(\mathrm{p}<0.001)$, class II restorations 
were at 1.63 times higher risk than class I restorations $(\mathrm{p}=0.023)$, and females were are 0.65 lower risk than males $(\mathrm{p}=0.030){ }^{42}$

\subsubsection{Geriatric and Special Patient Populations}

Provision and survival of dental restorations for patients living in residential care is complicated by their physical and cognitive impairments, financial barriers, limited access to care, poor $\mathrm{OH}$, and salivary hypofunction often due to polypharmacy. While all the patient, dentist, and material factors affecting restoration longevity for healthy adults equally affect geriatric and special patient populations, these patients typically have higher patient risk factors for caries due to poor plaque control, salivary gland hypofunction, multiple exposed root surfaces, and history of caries. ${ }^{81,82}$ For older adult patients, increased risk of tooth loss has been associated with partial removable dental prostheses and active caries and a synergistic effect when both are present. Hence, these patients require aggressive prevention regimens in combination with individualized operative treatment. Due to the increased number of risk factors decreasing restoration longevity in this population, numerous researchers have suggested older adults should have more frequent monitoring than younger patients (i.e. 3-month recall). ${ }^{82}$ The effect size of patient risk factors on the longevity of dental restorations has not been measured for frail older adults in previous studies.

\subsection{Study Rationale}

No published studies on the longevity of direct dental restorations in frail elderly patients living in LTC facilities currently exist. Therefore, this study was designed to determine the 5-year survival rate of direct dental restorations placed in frail older adults living in LTC to aid in dental 
treatment planning for this marginalized patient population. Specifically, there are no studies comparing the longevity of GIC and RC restorations for these patients.

In British Columbia in 2015, the average stay in LTC, which typically reflects time from admission to time of death for a frail elder living in LTC, was reported at 829 days (2.3 years). ${ }^{9}$ Of course, there are LTC patients who live substantially longer than this. From a dental treatment planning perspective, direct restorations should last at least this long to minimize morbidity (i.e. restoration replacement and/or tooth extraction) and cost to patients and their family. In the present study, we have chosen a 5-year survival rate to capture the life span of most patients living in LTC.

\subsection{Research Question}

1. What is the survival/longevity of tooth coloured dental restorations for frail older adults living in LTC?

2. Is there a survival difference between resin composite restorations and glass ionomer cement restorations in frail older adults living in LTC?

\subsection{Specific Aim}

To assess the survival of tooth coloured restorations (RC and GIC) in frail older adults in LTC. As a secondary objective, risk factors contributing to restoration longevity in the geriatric cohort were also examined and their effect size measured through multi-variable regression. These risk factors included $\mathrm{OH}$, age, gender, mobility status, and number of carious teeth at initial examination. 


\subsection{Hypothesis}

Null hypothesis: There is no difference in the failure rate of $\mathrm{RC}$ restorations compared to the failure rate of GIC restorations placed in frail older adults living in LTC over 5 years.

Study hypothesis: There is a difference in the failure rate of $\mathrm{RC}$ restorations compared to the failure rate of GIC restorations placed in frail older adults living in LTC over 5 years. 


\section{Chapter 2: Materials and Methods}

\subsection{Materials and Methods}

The University of British Columbia (UBC) Geriatric Dentistry Program (GDP), as a part of the UBC Faculty of Dentistry, has a mandate to provide clinical service, research, and education in dental geriatrics. The program has been providing clinical service and collecting data on their LTC patients since 2002, which was the source of data for this study. Prior to conducting this study, the Clinical Research Ethics Board at the University of British Columbia approved the study (UBC CREB Number: H1802077).

Data were acquired from two software programs used by the UBC GDP- Axium and Clinical Index of Oral Disorder in Elders (CODE) software. Axium is an academic dental management software used in many North American dental schools for clinical documentation, student management, and financial record-keeping. Financial records for direct dental restorations are stored in this software. CODE is an index created for use in residential-care populations to measure oral disorders in elders and has been previously used in descriptive and comparative research. ${ }^{6,16,17,79}$ This index measures jaw dysfunction, status of removable prostheses, soft tissues, teeth, and periodontium and gives individual and composite scores for each patient which can be used as a combined measure of a patient's oral status or disease burden. An odontogram is included in this software, which was used to track the status of teeth previously restored within the program.

Patients who had a direct RC or GIC dental restoration placed in the UBC Geriatric Dentistry Program between January 1, 2002 and Dec 31, 2012 were identified through Axium billing records using the following British Columbia Dental Association (BCDA) Fee Guide billing codes: 23101-23105, 2321123215, 23221-23225, 23111-23115, 23311-23315, 23321-23325. Prior to 2015, the BCDA had separate codes for RC and GI restorations. After 2015, the BCDA fee guide was modified to combine the two 
procedure codes into one universal code (i.e. one code for "tooth-coloured" restoration which can either be $\mathrm{RC}$ or GIC). Caries control restorations, which were billed as gross caries excavation followed by a temporary restoration, usually GIC, were also identified using the BCDA fee guide code 20111. The following information was associated with each restorative procedure: date of treatment, tooth number, surfaces (mesial, distal, occlusal/incisal, buccal, lingual), number of surfaces, restorative material (based on the BCDA billing code), patient age, and patient gender. For each patient, additional information was also available from the CODE examination electronic record, including medications, medical conditions, number of remaining teeth in maxilla/mandible, presence of removable prostheses in maxilla/mandible/both, mobility status, CODE tooth and overall scores, patient's ability to perform $\mathrm{OH}$, and caries status. Restorations used for data analysis reflected the most recent restorations provided to allow for a 5-year follow up and to reach an appropriate sample size, as described in the following section on sample size calculation.

The restorations used in data analysis were exclusively from frail older adult patients living in LTC facilities in the Greater Vancouver area. Restorations provided to community-dwelling older adults were identified and excluded from data analysis. Restorations were predominantly provided in dental clinics within the LTC facilities although a small number were provided at the GDP clinic at the UBC Faculty of Dentistry for patients transferred from LTC facilities without an on-site dental operatory. Restorations were provided by several different UBC GDP dentists. For patients residing in LTC facilities, a new patient examination or recall examination at their bedside in the LTC facility was provided and an individualized treatment plan prescribed by a GDP dentist prior to an operative dentistry appointment.

Each restoration was followed annually for up to five years using the CODE odontogram. In the odontogram, each tooth had two parameters- one for caries status (i.e. no caries, caries not involving the 
pulp, caries involving the pulp) and one for clinical condition (i.e. intact, fractured, unrestorable root, pontic, etc.). From year 1 to 5, each restoration was given a score of 0,1 , or 2 with the following criteria:

- Score 0: Represented a censored event (i.e. restoration lost to follow-up or the patient was deceased)

- Score 1: Represented restoration survival (i.e. the tooth was intact and had no caries present on the CODE odontogram and no subsequent procedures were performed on the tooth as per Axium billing records)

- Score 2: Represented restoration failure (i.e. the tooth had replacement of a restoration on the same tooth surfaces or extraction, as identified on Axium billing records. A score of 2 was also given if the tooth was identified on the CODE odontogram as being fractured or had caries (either involving the dental pulp or not involving the dental pulp))

For premolar or molar teeth that had a mesial-occlusal (MO) restoration placed, the subsequent placement of a distal-occlusal (DO) restoration was not considered a failure in this study as these typically represent two separate lesions and does not necessarily indicate that the original restoration failed. The same grading process was applied for class III lesions on anterior teeth. Endodontic treatment was not used as a failure criterion in this study as there were very low numbers of endodontic procedures present in our data set.

\subsubsection{Statistical Analysis and Sample Size Calculation}

Statistical analysis was planned in conjunction with statisticians in the Applied Statistics and Data Science (ASDa) Group through the Department of Statistics at UBC. Prior to conducting data collection and main analysis, a pilot study was conducted on a sample of restorations using UBC GDP data. This pilot study identified 154 tooth-coloured restorations placed by the UBC GDP in 2002 in LTC patients 
and performed data collection in the same way as described above for the main analysis. The pilot study reported a 5-year survival for RC and GIC of approximately 54\%. A hazard ratio of GIC relative to RC via the mixed-effect logistic regression was estimated at 1.37 (p>0.05). A target odds ratio between 1.369 and 1.418 would be roughly equivalent to this target hazard ratio of 1.37 , assuming the estimated survival probabilities for the RC group by the pilot study's logistic regression provides enough statistical precision. Sample size was estimated from the standard error for the odds ratio and was projected at 2,448-2,955 restorations at a power of $80 \%$.

Table 2-1 Sample Size Projection based on Pilot Study Results

\begin{tabular}{|c|c|c|c|c|c|c|}
\hline \multirow[b]{2}{*}{$\begin{array}{l}\text { Target odds ratio to } \\
\text { be detected }\end{array}$} & \multicolumn{3}{|c|}{ Power $=\mathbf{8 0} \%$} & \multicolumn{3}{|c|}{ Power $=90 \%$} \\
\hline & $\begin{array}{r}\text { Multiples of current } \\
\text { pilot study }\end{array}$ & $\begin{array}{l}\text { No. of } \\
\text { patients }\end{array}$ & $\begin{array}{r}\text { Projected no. of } \\
\text { restoration }\end{array}$ & $\begin{array}{r}\text { Multiples of current } \\
\text { pilot study }\end{array}$ & $\begin{array}{r}\text { No. of } \\
\text { patients }\end{array}$ & $\begin{array}{r}\text { Projected no. of } \\
\text { restoration }\end{array}$ \\
\hline 1.1 & 200.0 & 8998 & 29194 & 267.0 & 12017 & 38987 \\
\hline 1.2 & 56.1 & 2523 & 8186 & 74.4 & 3348 & 10862 \\
\hline 1.369 & 20.2 & 911 & 2955 & 26.4 & 1188 & 3856 \\
\hline 1.418 & 16.8 & 755 & 2448 & 21.8 & 979 & 3176 \\
\hline 1.531 & 12.0 & 539 & 1748 & 15.3 & 689 & 2237 \\
\hline 1.8 & 7.4 & 331 & 1073 & 9.1 & 410 & 1330 \\
\hline
\end{tabular}

The three objectives of statistical analysis were to estimate the yearly failure rates for RC and GIC restorations, compare these failure rates, and adjust for relevant covariates and measure their adjusted effect size. A mixed-effect logistic regression was selected to allow for one coherent longitudinal model to address these three goals. Each restoration still "at risk" (i.e. restoration intact and patient still alive) was assessed as a series of binary indicators of whether a failure has occurred in a calendar year up to drop-out or failure. The results of this regression were converted into cumulative survival probabilities 
and were combined over multiple years. Furthermore, the failure rates for RC and GIC were compared.

A mixed-effect model was selected to address the presence of within-patient correlation as many patients in the sample had multiple restorations placed in their mouth. These restorations are subjected to the same oral environment and patient factors (i.e. caries risk, hyposalivation, mobility status, medications, ability to perform oral self-care, etc.). A mixed-effect model addresses correlated data by treating multiple restorations placed in the same patient as clusters.

A high drop-out rate was present in our data as many patients passed away before the end of the 5-year follow-up period. The follow-up times of restorations for these patients were considered censored at the end of the calendar year in which they dropped out. Sample size calculation assumed the failure and censoring rates among patients to be sampled in the main analysis to be similar to those sampled in the pilot study.

The effect size of several covariates and their impact on failure rates of the two materials were measured through simple and multivariate odds ratios. Covariate data available for analysis included age, gender, numbers of remaining teeth, presence of a prosthesis, medical co-morbidities, nervous system diagnosis (i.e. dementia, Parkinson's disease, Huntington's disease, etc.), mobility status, presence of caries at initial exam, $\mathrm{OH}$, tooth structure CODE scores, and overall CODE scores. All covariate data were acquired from the CODE database. Selection of covariates was done by assessing the distribution of restorations for each variable and these baseline characteristics are described in the subsequent section.

Selected covariates were introduced into the mixed-effect logistic regression model and yielded an OR for each variable. Adjusted OR for covariates were presented in two separate tables. One table was adjusted only for treatment, time, and random effects while the second was adjusted for treatment, time, and 
random effects, as well as for the effects of all covariates simultaneously. The first table, representing an unadjusted model, provides a simple OR which measures the crude effect size of individual covariates (Table 3-5). The estimated effect does not take into account the effect of other covariates, which might also be correlated with the covariate. For example, if one wanted to determine the effect size of age or gender on restoration failure, this model would not be able to differentiate the effect size between the two covariates or whether there was another underlying variable affecting the outcome. In the second adjusted covariate model, one can estimate the effect size of individual covariates on top of the existing logistic model and measure their effect size independent of the other covariates (Table 3-7). For example, one could measure the effect size of gender on restoration failure independent of other possible variables. This represents the estimated difference in failure rate, in terms of $\mathrm{OR}$, between men and women who are otherwise identical with respect to other covariates. A chi-squared test was performed to identify statistically significant covariate at 0.05 significance level. $95 \%$ confidence intervals were also used to estimate the covariate effects. In our sub-analysis sample, there was missing CODE data for 277 restorations. Missing data was the result of either: 1 . human error in data entry or 2. incomplete CODE examination due to an un-cooperative patient.

Alternative statistical techniques that were considered included Kaplan-Meier survival analysis and Cox proportional hazards model. These two techniques have been previously used in the dental literature for survival studies on dental restorations. ${ }^{76}$ Kaplan-Meier survival analysis is a technique to examine survival rates and is commonly used when patients enter or drop out of studies at different times. It can be used to compute survival over time while accounting for censored observations. However, Kaplan-Meier survival analysis is not appropriate for correlated data (within-patient correlation). Cox proportional hazards model is for continuous time data whereas the data available in our sample is discrete (i.e. yearly). Furthermore, while a Cox model adjusts for and assesses covariates, it does not estimate annual 
failure rates. In the main analysis, crude survival probabilities were reported alongside the estimated survival probabilities from the mixed-effect regression model.

Data for this study was managed on encrypted computers within the UBC Faculty of Dentistry. All dental restorations included in the study had patient identifiers re-coded so individual restorations could not be identified. 


\section{Chapter 3: Results}

\subsection{Results}

A total of 3,201 tooth-coloured restorations were identified from the UBC GDP Axium records, representing 269 caries control restorations, 1,069 GIC, and 1,863 RC restorations. Caries control restorations were excluded from subsequent analysis. A total of 149 community-dwelling older adult patients were also identified and excluded from analysis. Furthermore, a total of 134 restorations were provided to adult patients ranging from 44-64 years of age, which are not representative of a geriatric LTC population, who were residing in LTC. These adult patients were residing in LTC typically due to traumatic brain injuries or due to substantial physical/mental disability. Restorations from this group were also excluded from analysis, leaving our study data composed of tooth-coloured restorations exclusively in frail older adults residing in LTC facilities. The final sample used for statistical analysis was 2,670 restorations placed in 786 patients (GIC or RC). This represents an over-sampling relative to the sample size estimate calculated from our pilot study. Restorations used in data analysis were composed of GIC or RC restorations placed between June 2007 to December 2012. Restorations placed in 2012 had a 5-year follow-up which ended in 2017.

The average number of restorations per patient was 3.4 in which 1.2 cases utilized GI and 2.2 cases used RC. Figure 3-1 shows the total number of restorations per patient, with most patients having had more than one restoration placed during the study period. Over the 5-year period, there was an increasing trend of RC usage and a decreasing trend of GIC usage (Figure 3-2). 


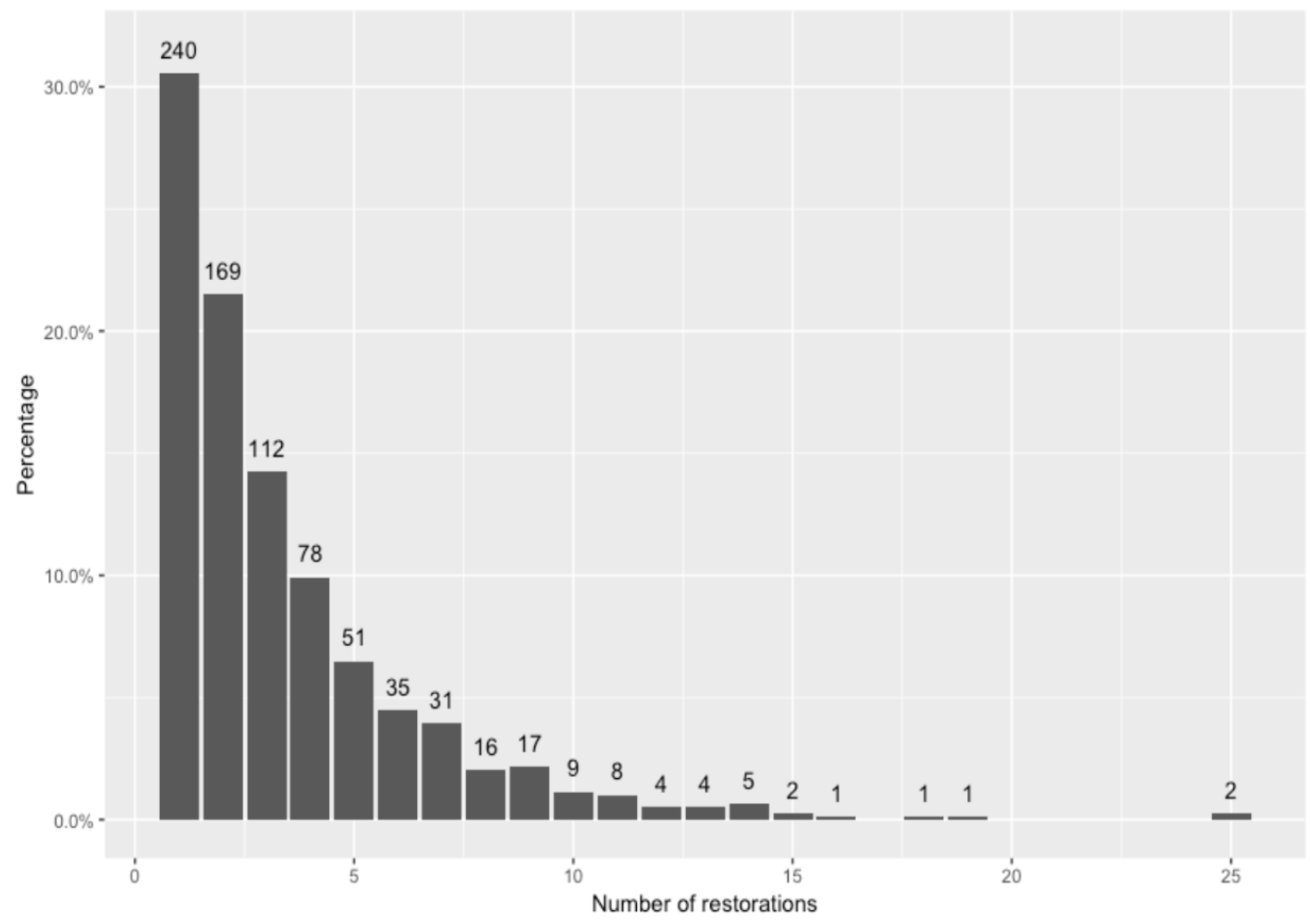

Figure 3-1 Total Number of Restorations per Patient, excluding Caries Control Restorations

Crude survival probabilities estimated by Kaplan-Meier method were reported in the survival curve below (Figure 3-3 and Table 3-1). The 5-year cumulative survival probability for RC and GIC was $60.5 \%$ and $59.4 \%$ respectively. 


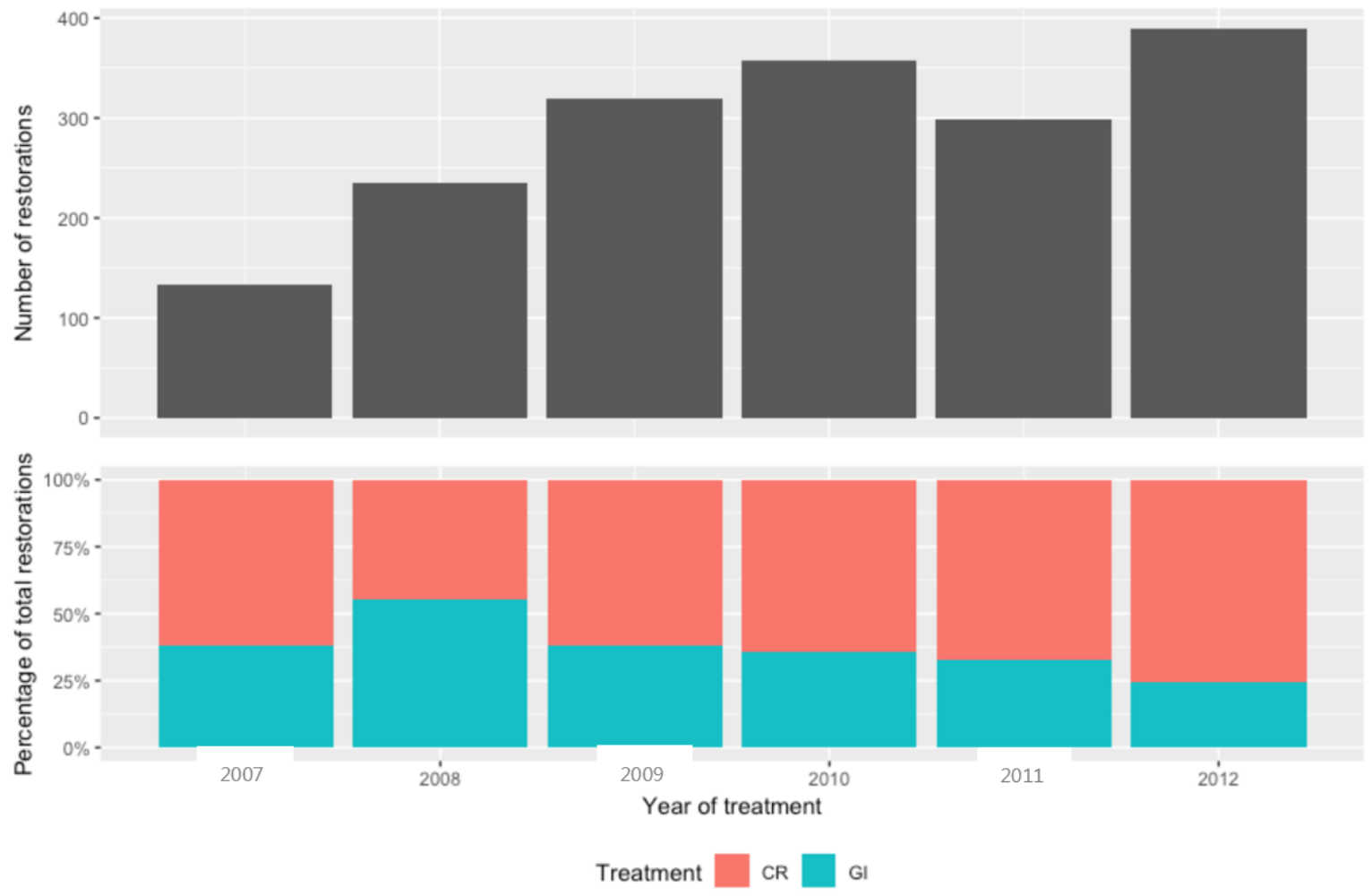

Figure 3-2 5-Year Trend of Total Restorations Placed and Restoration Material Usage 


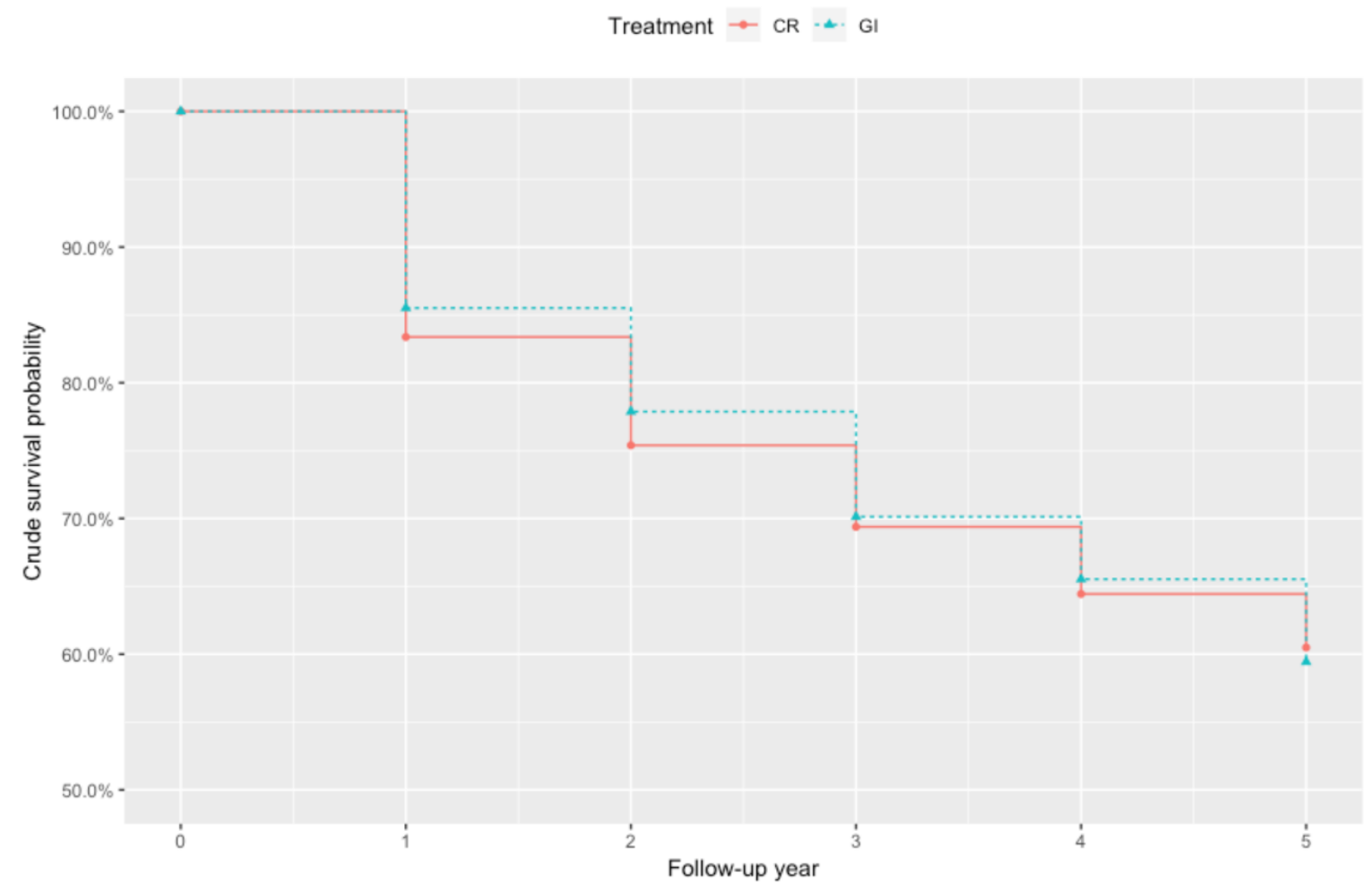

Figure 3-3 Crude Survival Probabilities for Tooth-Coloured Restorations

Table 3-1 Crude Survival Probabilities for Tooth-Coloured Restorations

\begin{tabular}{|l|l|l|l|}
\hline Outcome- Crude survival probabilities & RC & GIC & Overall \\
\hline Year 1 & $83.4 \%$ & $85.5 \%$ & $84.2 \%$ \\
\hline Year 2 & $75.4 \%$ & $77.9 \%$ & $76.3 \%$ \\
\hline Year 3 & $69.4 \%$ & $70.1 \%$ & $69.7 \%$ \\
\hline Year 4 & $64.4 \%$ & $65.5 \%$ & $64.9 \%$ \\
\hline Year 5 & $60.5 \%$ & $59.4 \%$ & $60.3 \%$ \\
\hline
\end{tabular}


Censoring rates for our study sample are described below (Table 3-2). On average, there was a $20-25 \%$ censoring rate each year due to restorations being lost to follow-up or deceased patients, similar to the conducted pilot study.

Table 3-2 Number of Restorations at risk, failed, and lost to follow-up

\begin{tabular}{|l|l|l|l|}
\hline Outcome- Teeth at-risk / Failure / Lost to follow-up & RC & GIC & Overall \\
\hline Year 1 & $1690 / 281 / 260$ & $980 / 142 / 211$ & $2670 / 423 / 471$ \\
\hline Year 2 & $1149 / 110 / 235$ & $627 / 56 / 179$ & $1776 / 166 / 414$ \\
\hline Year 3 & $803 / 64 / 220$ & $392 / 39 / 109$ & $1195 / 103 / 329$ \\
\hline Year 4 & $519 / 37 / 138$ & $244 / 16 / 99$ & $763 / 53 / 237$ \\
\hline Year 5 & $343 / 21 / 95$ & $129 / 12 / 38$ & $472 / 33 / 133$ \\
\hline
\end{tabular}




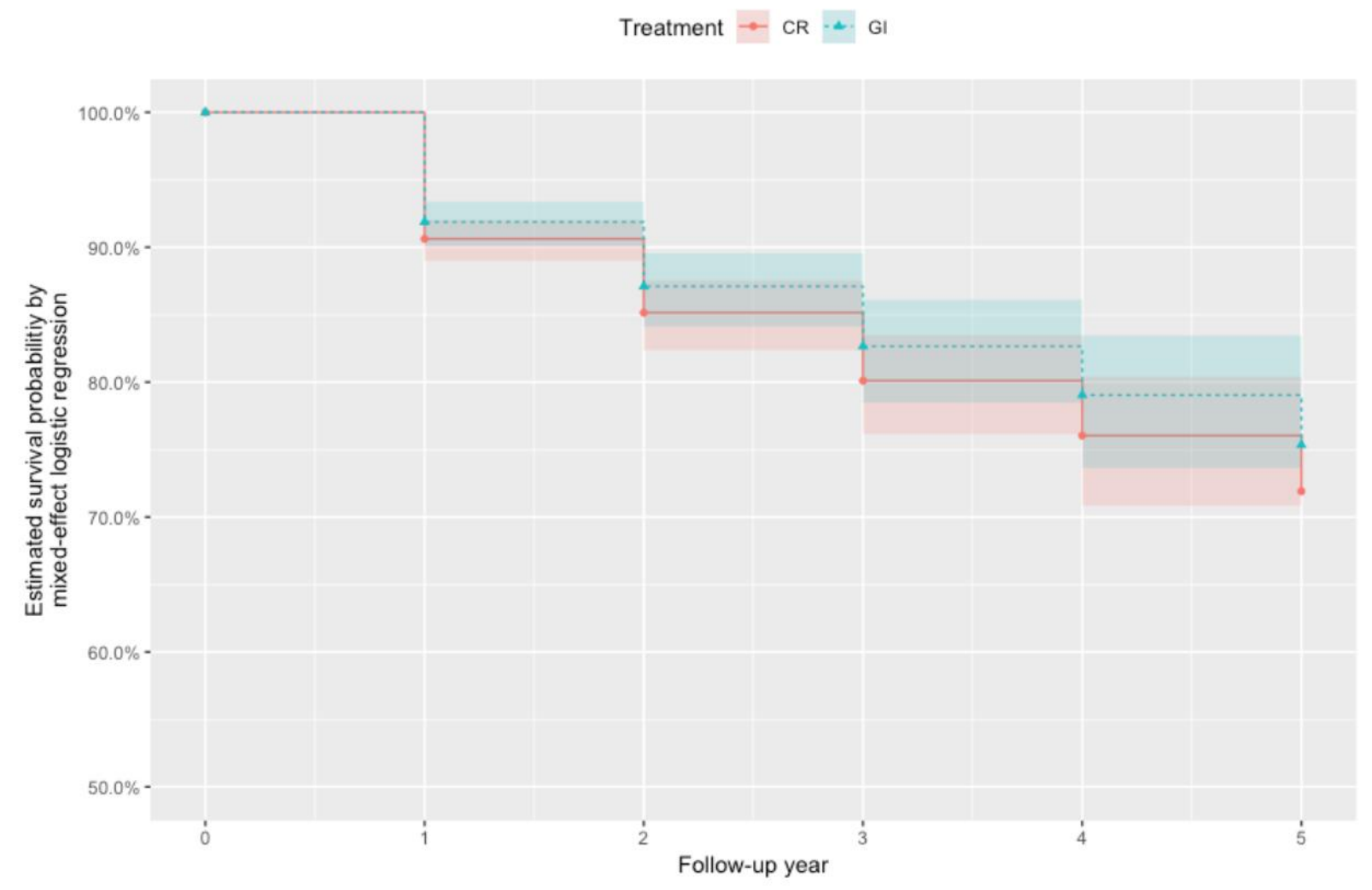

Figure 3-4 Mixed Effect Logistic Regression Model for 5-year Survival of Tooth-Coloured Restorations

Table 3-3 Odds Ratio from Mixed Effect Logistic Regression (Unadjusted Analysis)

\begin{tabular}{llll} 
Estimated odds ratio (GI vs CR) & Standard error & $95 \%$ confidence interval & P-value \\
\hline 0.854 & 0.095 & $(0.686,1.063)$ & 0.157
\end{tabular}

In the mixed-effect logistic regression, 5-year survival for both RC and GIC were close to the crude survival probabilities. The estimated OR of GIC relative to RC was $0.854(\mathrm{p}=0.157)$, therefore, there the null hypothesis cannot be rejected. 


\subsubsection{Sub-Analysis of Covariates}

Two models are presented for sub-analysis of covariates, including age, gender, remaining teeth, presence of a removable prosthesis, medical conditions, nervous system diagnoses (i.e. dementia, Parkinson's disease, etc), mobility status, caries, $\mathrm{OH}$, tooth structure CODE scores, and overall CODE scores. Sub-analysis could only be completed on patients in our sample with complete CODE data. Missing data was the result of human error or uncooperative patients not allowing a complete CODE exam. In our sample, there was missing data from 407 restorations, accounting for $14.5 \%$ of the total sample. Therefore, the results of sub-analysis are from CODE data from $85.5 \%$ of sampled restorations.

The baseline characteristics of the study population is described in the following table (Table 34): 
Table 3-4 Baseline Characteristics of Study Sample

\begin{tabular}{|c|c|c|c|}
\hline Baseline Characteristics & $\mathbf{R C}$ & GIC & Overall \\
\hline \multicolumn{4}{|l|}{ Number of teeth } \\
\hline $\mathrm{N}$ & 1690 & 980 & 2670 \\
\hline \multicolumn{4}{|l|}{ Age } \\
\hline Mean (SD) & $86.8(10.7)$ & $86.9(10.2)$ & $86.8(10.5)$ \\
\hline Median (Q1-Q3) & $87(81-92)$ & $86(80-91)$ & $87(80-91)$ \\
\hline Min-Max & $65-113$ & $65-113$ & $65-113$ \\
\hline \multicolumn{4}{|l|}{ Age Cohort, n (\%) } \\
\hline$<75$ & $237(14 \%)$ & $110(11.2 \%)$ & $347(13 \%)$ \\
\hline $75-85$ & $514(30.4 \%)$ & $308(31.4 \%)$ & $822(30.8 \%)$ \\
\hline $86-95$ & $702(41.5 \%)$ & $426(43.5 \%)$ & $1128(42.2 \%)$ \\
\hline$>95$ & $237(14 \%)$ & $136(13.9 \%)$ & $373(14 \%)$ \\
\hline \multicolumn{4}{|l|}{ Gender, n (\%) } \\
\hline Male & $579(34.3 \%)$ & $355(36.2 \%)$ & $934(35 \%)$ \\
\hline Female & $956(56.6 \%)$ & $529(54 \%)$ & $1485(55.6 \%)$ \\
\hline Missing data & $155(9.2 \%)$ & $96(9.8 \%)$ & $251(9.4 \%)$ \\
\hline \multicolumn{4}{|l|}{ Remaining Teeth, n (\%) } \\
\hline$<7$ & $158(9.3 \%)$ & $87(8.9 \%)$ & $245(9.2 \%)$ \\
\hline $7-20$ & $787(46.6 \%)$ & $492(50.2 \%)$ & $1279(47.9 \%)$ \\
\hline$>20$ & $604(35.7 \%)$ & $312(31.8 \%)$ & $916(34.3 \%)$ \\
\hline Missing data & $141(8.3 \%)$ & $89(9.1 \%)$ & $230(8.6 \%)$ \\
\hline \multicolumn{4}{|c|}{ Removable prosthesis, n (\%) } \\
\hline Wearing prosthesis & $702(41.5 \%)$ & $402(41 \%)$ & $1104(41.3 \%)$ \\
\hline No prosthesis & $910(53.8 \%)$ & $514(52.4 \%)$ & $1424(53.3 \%)$ \\
\hline Unknown & $78(4.6 \%)$ & $64(6.5 \%)$ & $142(5.3 \%)$ \\
\hline \multicolumn{4}{|c|}{ Number of co-morbidities, n (\%) } \\
\hline 1-3 co-morbidities & $660(39.1 \%)$ & $467(47.7 \%)$ & $1127(42.2 \%)$ \\
\hline$>4$ co-morbidities & $889(52.6 \%)$ & $421(43 \%)$ & $1310(49.1 \%)$ \\
\hline Missing & $141(8.3 \%)$ & $92(9.4 \%)$ & $233(8.7 \%)$ \\
\hline \multicolumn{4}{|c|}{ Nervous system diagnosis, $\mathrm{n}(\%)$} \\
\hline Yes & $1040(61.5 \%)$ & $623(63.6 \%)$ & $1663(62.3 \%)$ \\
\hline No & $509(30.1 \%)$ & $265(27 \%)$ & $774(29 \%)$ \\
\hline Missing & $141(8.3 \%)$ & $92(9.4 \%)$ & $233(8.7 \%)$ \\
\hline
\end{tabular}




\begin{tabular}{|c|c|c|c|}
\hline Baseline Characteristics & $\mathbf{R C}$ & GIC & Overall \\
\hline \multicolumn{4}{|l|}{ Mobility status, $\mathbf{n}(\%)$} \\
\hline Undefined & $6(0.4 \%)$ & $9(0.9 \%)$ & $15(0.6 \%)$ \\
\hline Ambulatory & $549(32.5 \%)$ & $326(33.3 \%)$ & $875(32.8 \%)$ \\
\hline Wheel Chair-bound & $893(52.8 \%)$ & $510(52 \%)$ & $1403(52.5 \%)$ \\
\hline Bedside & $101(6 \%)$ & $46(4.7 \%)$ & $147(5.5 \%)$ \\
\hline Missing & $141(8.3 \%)$ & $89(9.1 \%)$ & $230(8.6 \%)$ \\
\hline \multicolumn{4}{|l|}{ Caries at initial exam, n (\%) } \\
\hline Present & $1019(60.3 \%)$ & $584(59.6 \%)$ & $1603(60 \%)$ \\
\hline Absent & $530(31.4 \%)$ & $307(31.3 \%)$ & $837(31.3 \%)$ \\
\hline Unknown & $141(8.3 \%)$ & $89(9.1 \%)$ & $230(8.6 \%)$ \\
\hline \multicolumn{4}{|l|}{ Oral Hygiene, n (\%) } \\
\hline Can perform own $\mathrm{OH}$ & $717(42.4 \%)$ & $454(46.3 \%)$ & $1171(43.9 \%)$ \\
\hline Can perform with assistance & $410(24.3 \%)$ & $242(24.7 \%)$ & $652(24.4 \%)$ \\
\hline Cannot perform own $\mathrm{OH}$ & $343(20.3 \%)$ & $141(14.4 \%)$ & $484(18.1 \%)$ \\
\hline Missing & $79(4.7 \%)$ & $54(5.5 \%)$ & $133(5 \%)$ \\
\hline Unknown & $141(8.3 \%)$ & $89(9.1 \%)$ & $230(8.6 \%)$ \\
\hline \multicolumn{4}{|l|}{ Tooth structure CODE score, $\mathrm{n}(\%)$} \\
\hline 0 & $403(26.1 \%)$ & $230(25.8 \%)$ & $633(26 \%)$ \\
\hline 1 & $38(2.5 \%)$ & $32(3.6 \%)$ & $70(2.9 \%)$ \\
\hline 2 & $515(33.4 \%)$ & $271(30.4 \%)$ & $786(32.3 \%)$ \\
\hline 3 & $586(38 \%)$ & $357(40.1 \%)$ & $943(38.8 \%)$ \\
\hline Missing & $148(8.8 \%)$ & $90(9.2 \%)$ & $238(8.9 \%)$ \\
\hline \multicolumn{4}{|l|}{ Overall CODE score, n (\%) } \\
\hline 0 & $215(14 \%)$ & $155(17.4 \%)$ & $370(15.3 \%)$ \\
\hline 1 & $170(11.1 \%)$ & $92(0.3 \%)$ & $262(10.8 \%)$ \\
\hline 2 & $1061(69.1 \%)$ & $582(65.4 \%)$ & $1643(67.8 \%)$ \\
\hline 3 & $89(5.8 \%)$ & $61(6.9 \%)$ & $150(6.2 \%)$ \\
\hline Missing & $155(9.2 \%)$ & $90(9.2 \%)$ & $245(9.2 \%)$ \\
\hline \multicolumn{4}{|l|}{ Missing observations, n (\%) } \\
\hline With missing/undefined data set & $244(14.4 \%)$ & $154(15.7 \%)$ & $398(14.9 \%)$ \\
\hline With complete data set & $1446(85.6 \%)$ & $826(84.3 \%)$ & $2272(85.1 \%)$ \\
\hline
\end{tabular}


In the first model, which is adjusted only for treatment, time, and random effects, a chi-squared test for covariate effects was performed to determine statistically significant results for each individual covariate. In this model, the effect sizes of individual covariates cannot be measured independent of other covariates or underlying variables. Based on the chi-squared test, three covariates were statistically significant at the 0.05 level: remaining teeth $(\mathrm{OR}=0.505-0.743$, $\mathrm{p}=0.0078)$, removable prosthesis use $(\mathrm{OR}=1.400, \mathrm{p}=0.0209)$, and having a nervous system diagnosis $(\mathrm{OR}=0.621, \mathrm{p}=0.0026)$ (Tables 3-5 and 3-6). Other covariates in this model did not reach statistically significant levels. 
Table 3-5 Estimated Odds Ratios- Unadjusted model

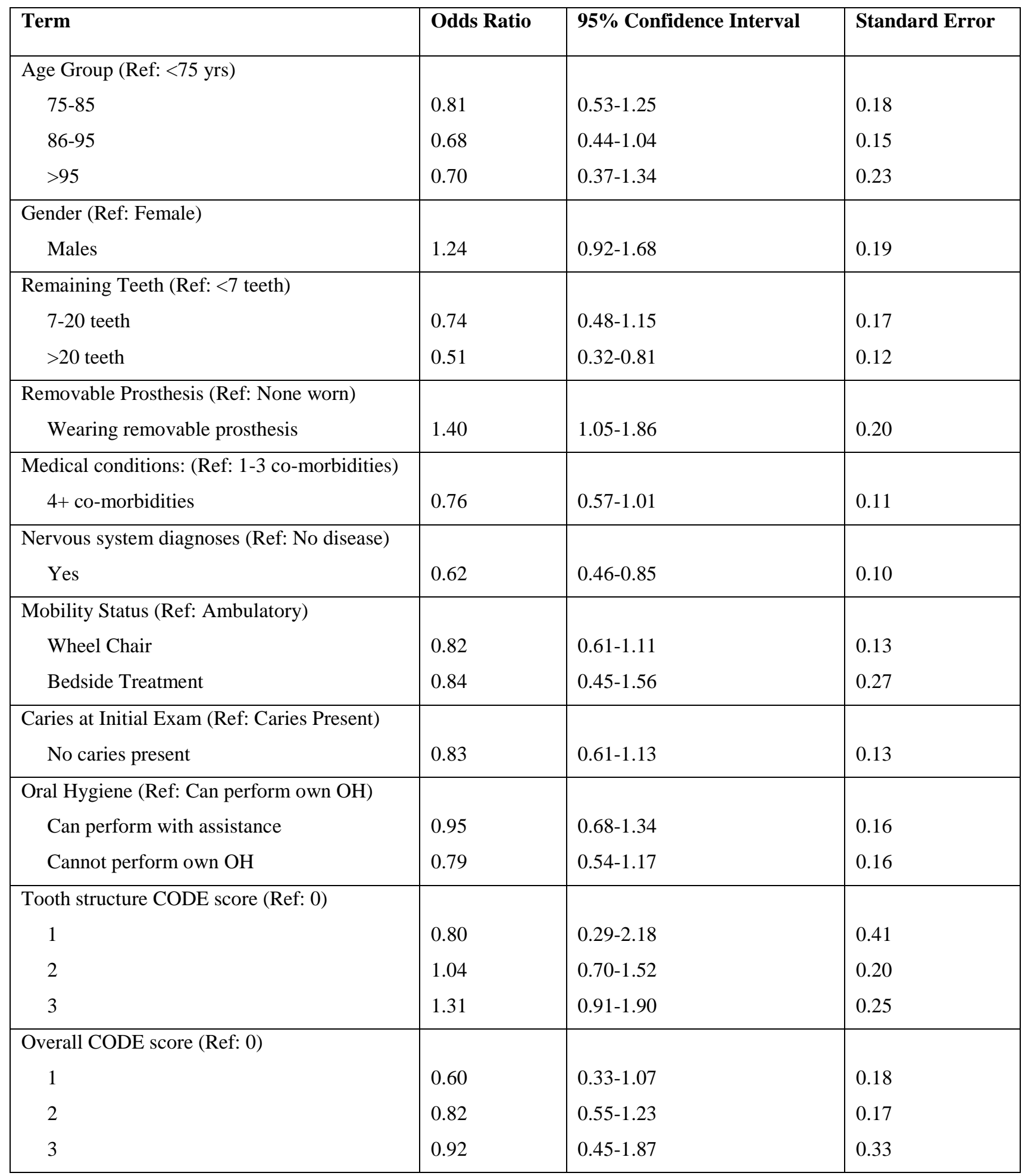


Table 3-6 Chi-squared tests for covariate effects (Type III Sum of Squares)- Unadjusted model

\begin{tabular}{|l|l|l|l|}
\hline Term & Chi Square statistic & Degrees of Freedom & p-value \\
\hline Age group & 3.75 & 3 & 0.289 \\
\hline Gender & 2.00 & 1 & 0.157 \\
\hline Remaining Teeth & 9.70 & 2 & 0.008 \\
\hline Removable Prosthesis & 5.33 & 1 & 0.021 \\
\hline Medical Conditions & 3.66 & 1 & 0.056 \\
\hline Nervous system diagnosis & 9.09 & 1 & 0.003 \\
\hline Mobility status & 1.61 & 2 & 0.441 \\
\hline Caries at Initial Exam & 1.44 & 1 & 0.231 \\
\hline Oral Hygiene & 1.37 & 2 & 0.505 \\
\hline Tooth Structure CODE Score & 3.37 & 3 & 0.338 \\
\hline Overall CODE Score & 3.17 & 3 & 0.366 \\
\hline
\end{tabular}

In the second model, adjusted for treatment, time, and random effects, only covariates with pvalues less than 0.100 from the chi-squared tests of the first models were included (Table 3-7). In this adjusted model, independent effect sizes of individual covariates can be measured while controlling for other covariates. These variables included age group, gender, remaining teeth, presence of a removable prosthesis, medical co-morbidities, and nervous system diagnoses. Again, a chi-squared test for treatment and covariate effects was performed (Table 3-8). Among the included covariates, only nervous system diagnoses $(\mathrm{OR}=0.683, \mathrm{p}=0.014)$ was statistically significant at $<0.050$ level. Other covariates were not significant in this model. 
Table 3-7 Estimated odds ratios for covariate-Adjusted Model

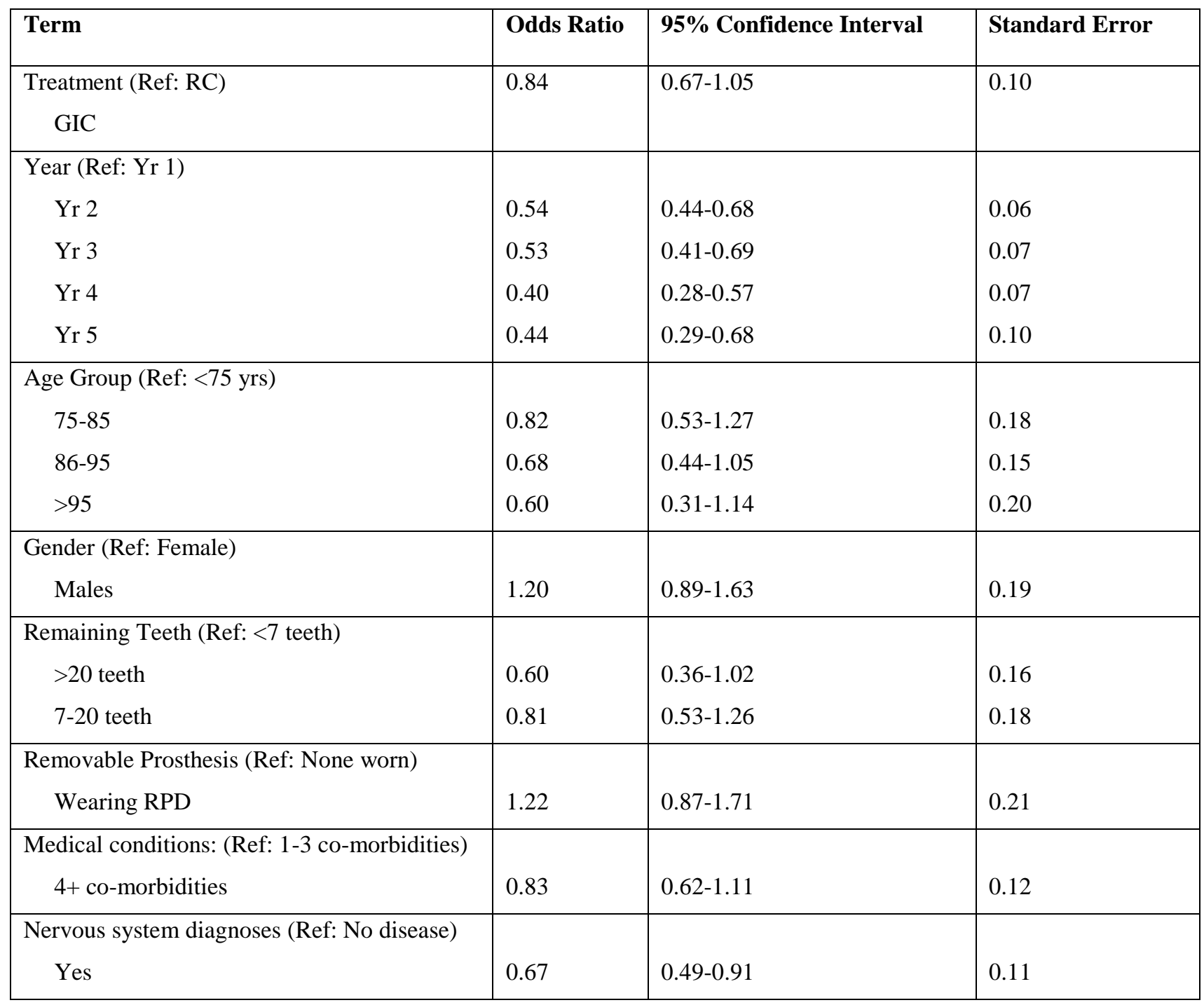


Table 3-8 Chi-squared tests for treatment and covariate effects (Type III Sum of Squares) -Adjusted Model

\begin{tabular}{|l|l|l|l|}
\hline Term & Chi Square statistic & Degrees of Freedom & p-value \\
\hline Treatment & 2.44 & 1 & 0.118 \\
\hline Year & 59.00 & 4 & 0.000 \\
\hline Age group & 4.35 & 3 & 0.226 \\
\hline Gender & 1.43 & 1 & 0.231 \\
\hline Remaining Teeth & 4.05 & 2 & 0.132 \\
\hline Removable Prosthesis & 1.28 & 1 & 0.257 \\
\hline Medical Conditions & 1.57 & 1 & 0.210 \\
\hline Nervous system diagnosis & 6.67 & 1 & 0.010 \\
\hline
\end{tabular}




\section{Chapter 4: Discussion}

This study examined the longevity of tooth-coloured dental restorations in frail older adults residing in LTC facilities. This vulnerable population is rapidly growing in Canada and has high levels of caries and other oral diseases. ${ }^{7,17}$ Our results suggest that tooth-coloured dental restorations have reasonable longevity in these patients and their survival is similar to survival probabilities reported in the literature for community-dwelling older adults. Specifically, our results can be contextualized relative to the studies of Caplan, Burke, and Keltjens that investigated restoration longevity in similar patient cohorts. In Caplan's study, 9,184 restorations in over 1,500 patients from the University of Iowa's Outpatient Geriatric and Special Needs clinic were followed and a re-intervention (i.e. re-restoration, extraction, or endodontic treatment) rate of $28.7 \%$ was reported. The patient cohort investigated in this study was composed of functionally independent, community-dwelling older adults who were able to attend appointments at the University of Iowa's dental clinic. A median survival for all restorations in this study was 6.2 years. ${ }^{76}$ The overall 5-year survival for direct restorations (AM, GIC, or RC) was estimated at approximately 50\% using a Kaplan-Meier survival curve, similar to the crude survival probabilities reported in the present study. Furthermore, multivariable regression from Caplan's study reported increased failure rates for molars and pre-molars compared to anterior teeth as well as increased failure rates for multi-surface restorations compared to single-surface restorations. ${ }^{76}$ In the Burke study utilizing data from the UK Dental Practice Board Database, sub-analysis on a group of patients over 70 years of age representing 30,000 patients reported a 5-year survival of $49 \% .{ }^{51}$ This British patient cohort also represented functionally independent older adults who could attend an outpatient dental clinic for restorative care. In another study investigating material choice to seal root canal orifices of overdenture abutments, a 4-year 
overall survival for $\mathrm{AM} / \mathrm{GIC} / \mathrm{RC}$ restorations was reported at $63 \%$ with no major differences noted between the different materials. ${ }^{83}$ The patient cohort in this study was also functionally independent adult patients who could attend an outpatient dental clinic. At present, there are no studies in the literature assessing restoration longevity specifically in LTC residents. However, the results from the studies of Caplan, Burke, and Keltjens report similar 5-year survival estimates to the present study.

The results from this study suggest restoration survival in frail older adult patients residing in LTC facilities is similar to functionally independent community-dwelling older adults, in spite of barriers to dental care and poor $\mathrm{OH}$. The results also suggest that direct dental restorations can be confidently provided to LTC patients to restore carious lesions, to maintain quality of life, chewing function, and dignity, and toprevent tooth loss. As previously discussed, good oral health is crucial to maintain function, minimize pain, and sustain social interaction. The need for dental restorations in this cohort is significant due to known Rapid Oral Health Deterioration in frail older adult patients. ${ }^{23}$

In British Columbia, the average stay in LTC is approximately 2.3 years. ${ }^{9}$ This time period typically reflects time of admission to the time of death. In the context of this study's results, this implies that the majority of restorations placed in LTC will not require re-intervention and serve the patient for their remaining lifetime. This aligns with the treatment-planning philosophy of rational dental care as it reduces patient morbidity and need for future invasive procedures, such as extractions or endodontic treatment. 
No significant differences were found between RC and GIC with regards to restoration longevity in our LTC patient cohort. This is likely because patient factors far outweigh operator and material factors, which each contribute to overall longevity. Patients residing in LTC typically have poor $\mathrm{OH}$, diets high in refined carbohydrates, salivary hypofunction secondary to polypharmacy which puts them at increased risk of caries. Our results support the continued use of GIC for LTC patients due to the numerous material advantages of GIC, notably its ease and speed of placement, especially in posterior and cervical regions of decay. RC should be utilized in anterior and aesthetic areas, providing adequate moisture control can be obtained.

This study does have several strengths and some inherent limitations. Due to the retrospective design, this study was one of restoration survival and not of restoration success. Unlike prospective studies that can provide double-blinded assessment of restorations in carefully controlled clinical environments, this study was only able to identify restoration failures from existing chart and financial records. Previous studies have employed similar study designs and suggested that retrospective studies or studies of re-intervention may be even more relevant to clinical practice than prospective studies as re-intervention rates are of great interest to clinicians. ${ }^{43,45}$ The key reason why our research question could be addressed with the available data set was because prior to 2015, there were separate fee codes for RC and GIC restorations. After 2015, these separate fee codes were joined into one code for "tooth-coloured dental restoration". This means both RC and GIC restorations were billed after 2015 using the same fee code. Our study performed a 5-year follow-up on restorations placed between 2007-2012, and, therefore, follow-up for some restorations was performed up until 2017. Future studies will be unable to retrospectively study differences in RC and GIC longevity using billing code data after 
2015 in British Columbia due to the fee guide changes. The study data revealed that there was increasing use of RC over the 5-year period and declining use of GIC, perhaps due to operator preference or aesthetic demands by patients. A nuanced look at material factors was not possible as procedural notes were not available for review. For example, information on the type of RC bonding system used, type of RC or GIC restorative material, use of rubber dam isolation, and restorative technique, all of which affect clinical performance, was not collected or assessed in this study.

Another significant difference in the design of this study compared to other similar studies was in data acquisition. While previous studies relied solely on electronic financial or chart records indicating a re-intervention (i.e. extraction, re-restoration, endodontic treatment, etc.), this study used these records as well as tooth status on the annual odontogram from the CODE program. This is a more precise measure of the true clinical status of individually restored teeth as it allows for a minimum of annual assessment of restored teeth. In all retrospective studies investigating restoration longevity, it is possible that previously placed restorations were replaced at other clinics, may fail prematurely without the patient's knowledge and have delayed replacement or never have subsequent re-intervention, or be lost to follow-up for other reasons. Nevertheless, the exact time of failure for every restoration is impossible to ascertain even in our data as the time of re-intervention does not necessarily relate to the time of failure. In addition, older patients typically under-report dental concerns. ${ }^{7}$

Data in this study was coded into three categories: 1 . Lost to follow-up or patient deceased (censored event), 2. Restoration survival, or 3. Restoration failure. When assigning scores for 
each restoration, we looked at financial and chart records first to ensure no replacements were provided. Replacement of restorations with the same surface was recorded as failures. However, for posterior teeth that had a MO restoration placed and then a subsequent DO restoration, the second restoration was not considered a re-restoration as this could represent two separate lesions. The same process was used for separate class III lesions on anterior teeth. Then, CODE odontograms were reviewed individually for each restoration for the 5-year follow-up period. Two parameters exist on this odontogram: one for caries status and one for tooth status. If the tooth was intact and had no caries present, the restoration was considered as a "survival." If the tooth was intact but had caries present (not obviously involving the pulp) and not re-restored the following year, it was also considered a "survival" as there is no indication on the odontogram as to the surface of the carious lesion. This was a limitation in this study as the caries recorded on the odontogram may relate to recurrent decay at the margin of the previously placed restoration or a primary lesion on a separate tooth surface.

Sub-analysis was performed in this study to explore the effect size of covariates on restoration longevity. Data available for sub-analysis included CODE demographics and information on age, gender, mobility status, among others. There was missing data from approximately $15 \%$ of our study population due to human error during data collection or uncooperative patients during the CODE examination. Previous studies have reported the effects of age and gender on restoration longevity, specifically that restorations in teenagers have higher rates of failure than healthy adult patients and that females have lower rates of restoration failure compared to men. ${ }^{40,42}$ Other studies have reported higher rates of caries in patients who wear removable prostheses. ${ }^{14}$ Our hypothesis on the effects of covariates on restoration longevity in the LTC cohort was that older, 
more physically or mentally disabled patients who had a compromised ability to perform daily $\mathrm{OH}$ would have higher risk of restoration failure. We also hypothesized that restoration survival would be more favourable for females compared to males, patients with a shortened dental arch compared to those with very few teeth, patients who did not wear a removable prosthesis, patients with fewer medical co-morbidities, patients who did not have a nervous system disease diagnosis (dementia, Parkinson's disease, etc.), and patients who were ambulatory compared to wheel-chair bound. Sub-analysis of these factors revealed no statistically significant results for any of these variables, except for patients with a nervous system disease diagnosis. This result, however, was paradoxical in that the OR reported showed a 0.67 lower likelihood of restoration failure for patients with a nervous system diagnosis $(\mathrm{p}<0.05)$. One possible explanation may be that these patients receive more daily $\mathrm{OH}$ attention and care than other patients in a LTC unit.

Future directions for research should include investigating the use of other materials in LTC patients, such as CAD/CAM composite and ceramics, and the use of dental caries preventive agents such as silver diamine fluoride. 


\section{Chapter 5: Conclusion}

The 5-year cumulative survival probability for RC and GIC was $60.5 \%$ and $59.4 \%$, respectively. Tooth-coloured dental restorations have reasonable longevity in frail older adult patients residing in LTC facilities. No statistically significant difference existed between RC and GIC materials with regards to restoration survival in this cohort over five years. There is a high need for restorative care in frail older LTC patients due to significant levels of oral disease related to high barriers to dental care, poor $\mathrm{OH}$, diets high in refined carbohydrates, and multimorbidity. Direct tooth-coloured restorations can be confidently provided to frail older adult patients residing in LTC in appropriate clinical scenarios to minimize tooth loss and maintain oral function, phonetics, and self-dignity. 


\section{References}

1. Statistics Canada. Census in brief: A portrait of the population aged 85 and older in 2016 in Canada. Updated 2018. Accessed December 4, 2018. https://www12.statcan.gc.ca/censusrecensement/2016/as-sa/98-200-x/2016004/98-200-x2016004-eng.cfm

2. Ortman JM, Velkoff V, Hogan H. An aging nation: The older population in the United States. US Census Bureau. 2014(Washington (DC)):25-1140. https://www.census.gov/library/publications/2014/demo/p25-1140.html

3. Prince, MJ., Wu, F., Guo, Y., Gutierrez Robledo, LM. The burden of disease in older people and implications for health policy and practice. Lancet. 2015;385(9967):549-562. doi: 10.2471/BLT.15.167726.

4. World Health Organization. World report on ageing and health. World Health Organization. 2015:260. https://www.who.int/ageing/events/world-report-2015-launch/en/

5. Zhang W, Wu YY, Wu B. Does oral health predict functional status in late life? Findings from a national sample. Journal of Aging and Health. 2017;30(6):924-944. http://journals.sagepub.com/doi/full/10.1177/0898264317698552. doi: $10.1177 / 0898264317698552$.

6. Maupomé G, Wyatt CCL, Williams PM, Aickin M, Gullion CM. Oral disorders in institutiondwelling elderly adults: A graphic representation. Special Care in Dentistry. 2002;22(5):194200. https://onlinelibrary.wiley.com/doi/abs/10.1111/j.1754-4505.2002.tb00270.x. doi: 10.1111/j.1754-4505.2002.tb00270.x.

7. Friedman PK, Kaufman LB, Karpas SL. Oral health disparity in older adults: Dental decay and tooth loss. Dental Clinics of North America. 2014;58(4):757.

8. Ardenghi DM, Wyatt C. Exploring the views of relatives of frail elderly patients about participating in a geriatric dentistry program. Special Care in Dentistry. 2017;37(3):140-146.

9. British Columbia Ministry of Health. Residential care staffing review. 2017.

https://www.health.gov.bc.ca/library/publications/year/2017/residential-care-staffing-review.pdf

10. Maarel-Wierink, C. D. van der, Vanobbergen JN, Bronkhorst EM, Schols JM, Baat Cd. Oral health care and aspiration pneumonia in frail older people: A systematic literature review.

Gerodontology. 2013;30(1):3-9.

https://www.narcis.nl/publication/RecordID/oai:repository.ubn.ru.nl:2066\%2F118904. doi:

10.1111/j.1741-2358.2012.00637.x.

11. Murray Thomson W. Epidemiology of oral health conditions in older people. Gerodontology. 2014;31 Suppl 1:9-16. https://www.ncbi.nlm.nih.gov/pubmed/24446974. 
12. Kassebaum NJ, Bernabé E, Dahiya M, Bhandari B, Murray CJL, Marcenes W. Global burden of untreated caries. Journal of Dental Research. 2015;94(5):650-658.

http://journals.sagepub.com/doi/full/10.1177/0022034515573272. doi:

10.1177/0022034515573272.

13. Chalmers JM, Carter KD, Spencer AJ. Caries incidence and increments in Adelaide nursing home residents. Special Care in Dentistry. 2005;25(2):96-105. https://onlinelibrary.wiley.com/doi/abs/10.1111/j.1754-4505.2005.tb01418.x. doi: 10.1111/j.1754-4505.2005.tb01418.x.

14. Chen X, Clark, Jennifer J.J., Naorungroj, Supawadee. Length of tooth survival in older adults with complex medical, functional and dental backgrounds. Journal of the American Dental Association. 2012;143(6):566-578. https://www.clinicalkey.es/playcontent/1-s2.0S0002817714608187. doi: 10.14219/jada.archive.2012.0235.

15. BC Ministry of Health. Long-term residential care. https://www2.gov.bc.ca/gov/content/health/accessing-health-care/home-community-care/careoptions-and-cost/long-term-residential-care. Updated 20192019.

16. Wyatt CCL, So FHC, Williams PM, Mithani A, Zed CM, Yen EHK. The development, implementation, utilization and outcomes of a comprehensive dental program for older adults residing in long-term care facilities. Journal (Canadian Dental Association). 2006;72(5):419. https://www.ncbi.nlm.nih.gov/pubmed/16772065.

17. Wyatt CCL. A 5-year follow-up of older adults residing in long-term care facilities: Utilisation of a comprehensive dental programme. Gerodontology. 2009;26(4):282-290. doi: 10.1111/j.1741-2358.2009.00305.x.

18. Kambhu PP, Warren JJ, Hand JS, Levy SM, Cowen HJ. Dental treatment outcomes among dentate nursing facility residents: An initial study. Special Care in Dentistry. 1998;18(3):128132. http://www.ncbi.nlm.nih.gov/pubmed/9680924. doi: 10.1111/j.1754-4505.1998.tb00918.x.

19. MacEntee MI, Wyatt CC. An index of clinical oral disorder in elders (CODE). Gerodontology. 1999;16(2):85-96. https://www.ncbi.nlm.nih.gov/pubmed/10825847. doi: 10.1111/j.1741-2358.1999.00085.x.

20. Tavares M, Lindefjeld Calabi KA, San Martin L. Systemic diseases and oral health. Dental Clinics of North America. 2014;58(4):797-814. https://www.clinicalkey.es/playcontent/1-s2.0-

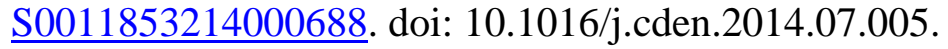

21. Ouanounou A, Haas DA. Pharmacotherapy for the elderly dental patient. Journal (Canadian Dental Association). 2015;80:f18. https://www.ncbi.nlm.nih.gov/pubmed/26679331. 
22. Brennan LJ, Strauss J. Cognitive impairment in older adults and oral health considerations: Treatment and management. Dental Clinics of North America. 2014;58(4):815. https://www.ncbi.nlm.nih.gov/pubmed/25201544.

23. Kossioni AE, Hajto-Bryk J, Janssens B, et al. Practical guidelines for physicians in promoting oral health in frail older adults. Journal of the American Medical Directors Association. 2018;19(12):1039-1046. https://www.ncbi.nlm.nih.gov/pubmed/30471798. doi: 10.1016/j.jamda.2018.10.007.

24. Canadian Dental Association. Best practices for aging adults in private dental practice. The Dental Assistant. 2012:38-47.

25. Seniors' Oral Health Secretariat. Oral health care delivery in residential care facilities. 2011. https://www.bcdental.org/WorkArea/DownloadAsset.aspx?id=6450

26. Ettinger RL. Clinical decision making in the dental treatment of the elderly. Gerodontology. 1984;3(2):157. https://www.ncbi.nlm.nih.gov/pubmed/6239819.

27. McComb D. Operative dentistry considerations for the elderly. The Journal of Prosthetic Dentistry. 1994;72(5):517-524.

https://www.sciencedirect.com/science/article/pii/0022391394901252. doi: 10.1016/00223913(94)90125-2.

28. da Mata C, Allen PF, Cronin M, O'Mahony D, McKenna G, Woods N. Cost-effectiveness of ART restorations in elderly adults: A randomized clinical trial. Community Dentistry and Oral Epidemiology. 2014;42(1):79-87.

http://onlinelibrary.wiley.com/doi/10.1111/cdoe.12066/abstract. doi: 10.1111/cdoe.12066.

29. da Mata C, Allen PF, McKenna G, Cronin M, O’Mahony D, Woods N. Two-year survival of ART restorations placed in elderly patients: A randomised controlled clinical trial. Journal of Dentistry. 2015;43(4):405-411. https://www.clinicalkey.es/playcontent/1-s2.0-

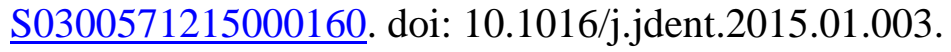

30. da Mata C, Cronin M, O'Mahony D, McKenna G, Woods N, Allen PF. Subjective impact of minimally invasive dentistry in the oral health of older patients. Clinical oral investigations. 2015;19(3):681-687. http://www.ncbi.nlm.nih.gov/pubmed/25084740. doi: 10.1007/s00784-0141290-6.

31. Anusavice K. Phillips' science of dental materials- 12th edition. Elsevier; 2013.

32. Demarco F, Corrêa M, Cenci M, Moraes R, Opdam N. Longevity of posterior composite restorations: Not only a matter of materials. Dental Materials. 2012;28(1):87-101. https://www.clinicalkey.es/playcontent/1-s2.0-S0109564111008311. doi:

10.1016/j.dental.2011.09.003. 
33. Borgia E, Baron R, Borgia J. Quality and survival of direct light-activated composite resin restorations in posterior teeth: A 5- to 20-year retrospective longitudinal study. Journal of Prosthodontics. 2019;28(28):195-203.

34. Jablonski RY, Barber MW. Restorative dentistry for the older patient cohort. British Dental Journal. 2015;218(6):337. http://www.ncbi.nlm.nih.gov/pubmed/25812883. doi:

10.1038/sj.bdj.2015.197.

35. Peumans M, Kanumilli P, De Munck J, Van Landuyt K, Lambrechts P, Van Meerbeek B. Clinical effectiveness of contemporary adhesives: A systematic review of current clinical trials. Dental Materials. 2005;21(9):864-881. https://www.sciencedirect.com/science/article/pii/S0109564105001156. doi: 10.1016/j.dental.2005.02.003.

36. van Dijken, J. W. V, Kieri C, Carlén M. Longevity of extensive class II open-sandwich restorations with a resin-modified glass-ionomer cement. Journal of Dental Research. 1999;78(7):1319-1325. http://journals.sagepub.com/doi/full/10.1177/00220345990780070601. doi: $10.1177 / 00220345990780070601$.

37. Scholtanus JD, Özcan M. Clinical longevity of extensive direct composite restorations in amalgam replacement: Up to 3.5 years follow-up. Journal of Dentistry. 2014;42(11):1404-1410. https://www.clinicalkey.es/playcontent/1-s2.0-S0300571214001900. doi:

10.1016/j.jdent.2014.06.008.

38. Hickel R, Peschke A. FDI world dental federation: Clinical criteria for the evaluation of direct and indirect restorations- update and clinical examples. Clinical Oral Investigations. 2010;14:349-366. doi: DOI 10.1007/s00784-010-0432-8.

39. Manhart J, Chen H, Hamm G, Hickel R. Buonocore memorial lecture. Review of the clinical survival of direct and indirect restorations in posterior teeth of the permanent dentition. Operative Dentistry. 2004;29(5):481. http://www.ncbi.nlm.nih.gov/pubmed/15470871.

40. Kim K, Namgung C, Cho B. The effect of clinical performance on the survival estimates of direct restorations. Restorative Dentistry \& Endodontics. 2013;38(1):11-20.

http://synapse.koreamed.org/search.php? where $=$ aview $\&$ id $=10.5395 /$ rde $.2013 .38 .1 .11 \&$ code $=218$ 5RDE\&vmode=FULL. doi: 10.5395/rde.2013.38.1.11.

41. Naghipur S, Pesun, Igor, DMD, MS, Nowakowski, Anthony, BSc, DMD, Kim, Aaron, BSc, DMD. Twelve-year survival of 2-surface composite resin and amalgam premolar restorations placed by dental students. Journal of Prosthetic Dentistry. 2016;116(3):336-339. https://www.clinicalkey.es/playcontent/1-s2.0-S0022391316001463. doi: 10.1016/j.prosdent.2016.02.005. 
42. Rho Y, Namgung C, Jin B, Lim B, Cho B. Longevity of direct restorations in stress-bearing posterior cavities: A retrospective study. Operative Dentistry. 2013;38(6):572-582.

http://www.ncbi.nlm.nih.gov/pubmed/23550914. doi: 10.2341/12-432-C.

43. Sande, F H van de, Opdam NJM, Rodolpho PA, Correa MB, Demarco FF, Cenci MS. Patient risk factors' influence on survival of posterior composites. Journal of Dental Research. 2013;92(7_suppl):83S. http://www.narcis.nl/publication/RecordID/oai:repository.ubn.ru.nl:2066\%2F119165. doi: 10.1177/0022034513484337.

44. Mjör IA, Dahl JE, Moorhead JE. Age of restorations at replacement in permanent teeth in general dental practice. Acta Odontologica. 2000;58(3):97-101.

http://www.ingentaconnect.com/content/apl/sodo/2000/00000058/00000003/art00001?crawler=tr ue. doi: 10.1080/000163500429208.

45. Mjor, IA. Shen, C., Eliasson, ST. Richter, S. Placement and replacement of restorations in general dental practice in iceland\&nbsp;

. Operative Dentistry. 2002;27:117-123.

46. Cruz Gonzalez AC, Marín Zuluaga DJ. Clinical outcome of root caries restorations using ART and rotary techniques in institutionalized elders. Brazilian Oral Research. 2016;30(1). http://www.ncbi.nlm.nih.gov/pubmed/27253146. doi: 10.1590/1807-3107BOR-2016.vol30.0063.

47. Amorim RGd, Leal SC, Frencken, J E F M. Survival of atraumatic restorative treatment (ART) sealants and restorations: A meta-analysis. Clin Oral Invest. 2012;16(2):429-441. http://www.narcis.nl/publication/RecordID/oai:repository.ubn.ru.nl:2066\%2F109650. doi: 10.1007/s00784-011-0513-3.

48. Lo ECM, Luo Y, Tan HP, Dyson JE, Corbet EF. ART and conventional root restorations in elders after 12 months. Journal of Dental Research. 2006;85(10):929-932.

http://journals.sagepub.com/doi/full/10.1177/154405910608501011. doi:

$10.1177 / 154405910608501011$.

49. Prakki A, Nunes MCP, Cefaly DFG, Lauris JRP, Navarro MFL. Six-year evaluation of the atraumatic restorative treatment approach in permanent-tooth class III restorations. Journal of Adhesive Dentistry. 2008;10(3):233. http://www.ncbi.nlm.nih.gov/pubmed/18652273.

50. Laske M, Opdam NJM, Bronkhorst EM, Braspenning JCC, Huysmans, Marie Charlotte D N J M. Longevity of direct restorations in Dutch dental practices. Descriptive study out of a practice based research network. Journal of Dentistry. 2016;46:12-17. https://www.clinicalkey.es/playcontent/1-s2.0-S0300571216300021. doi:

10.1016/j.jdent.2016.01.002.

51. Burke FJT, Lucarotti PSK, Holder RL. Outcome of direct restorations placed within the general dental services in england and wales (part 2): Variation by patients' characteristics. 
Journal of Dentistry. 2005;33(10):817-826.

https://www.sciencedirect.com/science/article/pii/S0300571205001405. doi:

10.1016/j.jdent.2005.03.007.

52. Lucarotti PSK, Holder RL, Burke FJT. Outcome of direct restorations placed within the general dental services in england and wales (part 1): Variation by type of restoration and reintervention. Journal of Dentistry. 2005;33(10):805-815. https://www.sciencedirect.com/science/article/pii/S0300571205001417. doi: 10.1016/j.jdent.2005.03.008.

53. Opdam NJM, Bronkhorst EM, Loomans BAC, Huysmans, M C D N J M. 12-year survival of composite vs. amalgam restorations. Journal of Dental Research. 2010;89(10):1063-1067. http://www.narcis.nl/publication/RecordID/oai:repository.ubn.ru.nl:2066\%2F89725. doi: $10.1177 / 0022034510376071$.

54. Burke FJT, Wilson NHF, Cheung SW, Mjör IA. Influence of patient factors on age of restorations at failure and reasons for their placement and replacement. Journal of Dentistry. 2001;29(5):317-324. https://www.sciencedirect.com/science/article/pii/S0300571201000227. doi: $10.1016 / \mathrm{S} 0300-5712(01) 00022-7$.

55. Opdam NJ, Sande, F H van de, Bronkhorst E, et al. Longevity of posterior composite restorations: A systematic review and meta-analysis. Journal of Dental Research. 2014;93(10):943-949. http://www.narcis.nl/publication/RecordID/oai:repository.ubn.ru.nl:2066\%2F138566. doi: $10.1177 / 0022034514544217$.

56. Kopperud SE, Tveit AB, Gaarden T, Sandvik L, Espelid I. Longevity of posterior dental restorations and reasons for failure. European Journal of Oral Sciences. 2012;120(6):539-548. http://onlinelibrary.wiley.com/doi/10.1111/eos.12004/abstract. doi: 10.1111/eos.12004.

57. Beck F, Lettner S, Graf A, et al. Survival of direct resin restorations in posterior teeth within a 19-year period (1996-2015): A meta-analysis of prospective studies. Dental Materials. 2015;31(8):958-985. https://www.clinicalkey.es/playcontent/1-s2.0-S010956411500144X. doi: 10.1016/j.dental.2015.05.004.

58. da Rosa Rodolpho, Paulo Antônio, Cenci MS, Donassollo TA, Loguércio AD, Demarco FF. A clinical evaluation of posterior composite restorations: 17-year findings. Journal of Dentistry. 2006;34(7):427-435. https://www.sciencedirect.com/science/article/pii/S0300571205001818. doi: 10.1016/j.jdent.2005.09.006.

59. Simecek JW, Diefenderfer KE, Cohen ME. An evaluation of replacement rates for posterior resin-based composite and amalgam restorations in U.S. navy and marine corps recruits. Journal of the American Dental Association. 2009;140(2):200-209.

https://www.clinicalkey.es/playcontent/1-s2.0-S0002817714642835. doi: 10.14219/jada.archive.2009.0134. 
60. Forss H, Widström E. Reasons for restorative therapy and the longevity of restorations in adults. Acta Odontologica. 2004;62(2):82-86.

http://www.ingentaconnect.com/content/apl/sodo/2004/00000062/00000002/art00005?crawler=tr ue. doi: 10.1080/00016350310008733.

61. Bernardo M, Luis H, Martin MD, et al. Survival and reasons for failure of amalgam versus composite posterior restorations placed in a randomized clinical trial. Journal of the American Dental Association. 2007;138(6):775-783. https://www.clinicalkey.es/playcontent/1-s2.0S0002817714623953. doi: 10.14219/jada.archive.2007.0265.

62. Opdam N, Bronkhorst E, Roeters J, Loomans B. Longevity and reasons for failure of sandwich and total-etch posterior composite resin restorations. Journal of Adhesive Dentistry. 2007;9:469-475.

63. Van Nieuwenhuysen J-, D'Hoore W, Carvalho J, Qvist V. Long-term evaluation of extensive restorations in permanent teeth. Journal of Dentistry. 2003;31(6):395-405.

https://www.sciencedirect.com/science/article/pii/S0300571203000848. doi: 10.1016/S03005712(03)00084-8.

64. Forss H, Widström E. From amalgam to composite: Selection of restorative materials and restoration longevity in Finland. Acta Odontologica. 2001;59(2):57-62. http://www.ingentaconnect.com/content/apl/sodo/2001/00000059/00000002/art00002. doi: $10.1080 / 000163501750157090$.

65. Collins CJ, Bryant RW, Hodge K-V. A clinical evaluation of posterior composite resin restorations: 8-year findings. Journal of Dentistry. 1998;26(4):311-317. https://www.sciencedirect.com/science/article/pii/S0300571297000195. doi: 10.1016/S03005712(97)00019-5.

66. Rasines Alcaraz MG, Veitz-Keenan A, Sahrmann P, Schmidlin PR, Davis D, Iheozor-Ejiofor Z. Direct composite resin fillings versus amalgam fillings for permanent or adult posterior teeth. The Cochrane database of systematic reviews. 2014(3):CD005620. http://www.ncbi.nlm.nih.gov/pubmed/24683067.

67. Laccabue M, Ahlf RL, Simecek JW. Frequency of restoration replacement in posterior teeth for U.S. navy and marine corps personnel. Operative Dentistry. 2014;39(1):43-49. http://www.ncbi.nlm.nih.gov/pubmed/23802636. doi: 10.2341/12-406-C.

68. EI-Mowafy OM, Lewis DW, Benmergui C, Levinton C. Meta-analysis on long-term clinical performance of posterior composite restorations. Journal of Dentistry. 1994;22(1):33-43. https://www.sciencedirect.com/science/article/pii/0300571294901430. doi: 10.1016/03005712(94)90143-0.

69. Da Rosa Rodolpho, Paulo A, Donassollo TA, Cenci MS, et al. 22-year clinical evaluation of the performance of two posterior composites with different filler characteristics. Dental 
Materials. 2011;27(10):955-963. https://www.clinicalkey.es/playcontent/1-s2.0-

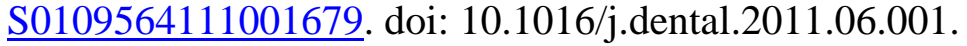

70. van Dijken JWV. Retention of a resin-modified glass ionomer adhesive in non-carious cervical lesions. A 6-year follow-up. Journal of Dentistry. 2005;33(7):541-547. https://www.sciencedirect.com/science/article/pii/S0300571205000096. doi: 10.1016/j.jdent.2004.11.015.

71. Powell LV, Johnson GH, Gordon GE. Factors associated with clinical success of cervical abrasion/erosion restorations. Operative Dentistry. 1995;20:7-13.

72. Namgung C, Rho YJ, Jin BH, Lim BS, Cho BH. A retrospective clinical study on cervical restorations: Longevity and failure-prognostic variables. Operative Dentistry. 2013;38(4):376385 .

73. Boing TF, de Geus JL, Wambier LM, Loguercio AD, Reis A, Gomes OMM. Are glassionomer cement restorations in cervical lesions more long-lasting than resin-based composite resins? A systematic review and meta-analysis. Journal of Adhesive Dentistry. 2018;20(5):435. https://www.ncbi.nlm.nih.gov/pubmed/30349908.

74. Miyamoto T, Morgano SM, Kumagai T, Jones, JA, Nunn, Martha E. Treatment history of teeth in relation to the longevity of the teeth and their restorations: Outcomes of teeth treated and maintained for 15 years. Journal of Prosthetic Dentistry. 2007;97(3):150-156. https://www.clinicalkey.es/playcontent/1-s2.0-S0022391307000509. doi: 10.1016/j.prosdent.2007.01.007.

75. Soncini JA, Maserejian NN, Trachtenberg F, Tavares M, Hayes C. The longevity of amalgam versus compomer/composite restorations in posterior primary and permanent teeth: Findings from the new england children's amalgam trial. Journal of the American Dental Association. 2007;138(6):763. http://jada.ada.org/cgi/content/abstract/138/6/763.

76. Caplan DJ, Li Y, Wang W, et al. Dental restoration longevity among geriatric and special needs patients. JDR Clinical \& Translational Research. 2018;4(1):41-48. https://journals.sagepub.com/doi/full/10.1177/2380084418799083. doi: $10.1177 / 2380084418799083$.

77. Hu JY, Chen XC, Li YQ, Smales RJ, Yip KH. Radiation-induced root surface caries restored with glassionomer cement placed in conventional and ART cavity preparations: Results at two years. Australian Dental Journal. 2005;50(3):186-190. http://onlinelibrary.wiley.com/doi/10.1111/j.1834-7819.2005.tb00359.x/abstract. doi: 10.1111/j.1834-7819.2005.tb00359.x.

78. Honkala S, Honkala E. Atraumatic dental treatment among Finnish elderly persons. Journal of Oral Rehabilitation. 2002;29:435-440. 
79. Maupomé G, Gullion CM, White BA, Wyatt CCL, Williams PM. Oral disorders and chronic systemic diseases in very old adults living in institutions. Special Care in Dentistry. 2003;23(6):199-208. https://onlinelibrary.wiley.com/doi/abs/10.1111/j.17544505.2003.tb00313.x. doi: 10.1111/j.1754-4505.2003.tb00313.x.

80. Christensen LB, Bardow A, Ekstrand K, et al. Root caries, root surface restorations and lifestyle factors in adult danes. Acta Odontologica Scandinavica. 2014;73(6):467-473. http://www.ncbi.nlm.nih.gov/pubmed/25467782. doi: 10.3109/00016357.2014.986753.

81. Hayes M, Da Mata C, Cole M, McKenna G, Burke F, Allen F. Risk indicators associated with root caries in independently living older adults. Journal of Dentistry. 2016;51:8-14. https://www.clinicalkey.es/playcontent/1-s2.0-S0300571216300926. doi: 10.1016/j.jdent.2016.05.006.

82. Singh, Mabi L., DMD, MS|Papas, Athena, DMD, PhD. Oral implications of polypharmacy in the elderly. Dental Clinics of North America. 2014;58(4):783-796.

https://www.clinicalkey.es/playcontent/1-s2.0-S0011853214000676. doi:

10.1016/j.cden.2014.07.004.

83. Keltjens HMAM, Creugers NHJ, Creugers TJ, van't Hof MA. A 4-year clinical study on amalgam, resin composite and resin-modified glass ionomer cement restorations in overdenture abutments. Journal of Dentistry. 1999;27(8):551-555.

https://www.sciencedirect.com/science/article/pii/S0300571299000329. doi: 10.1016/S03005712(99)00032-9.

84. Jones P, Kennedy, S. Clearing the Haze: Managing Care for seniors with cognitive impairment. The Bridge. British Columbia Dental Association. 2018;(1):8-11.

85. Sidhu SK, Schmalz G. The biocompatibility of glass-ionomer cement materials: A status report for the American Journal of Dentistry. American Journal of Dentistry. 2001; 14(6):38796. 